\title{
Voltage and Frequency Control of Balanced/Unbalanced Distribution System Using the SMES System in the Presence of Wind Energy
}

\author{
Hossam S. Salama ${ }^{1,2}$ and Istvan Vokony $1, *(\mathbb{D}$ \\ 1 Department of Electric Power Engineering, Budapest University of Technology and Economics, \\ 1111 Budapest, Hungary; hossam.salama@vet.bme.hu \\ 2 Department of Electrical Engineering, Faculty of Engineering, Aswan University, Aswan 81542, Egypt \\ * Correspondence: vokony.istvan@vet.bme.hu; Tel.: +36-702-533-589
}

Citation: Salama, H.S.; Vokony, I. Voltage and Frequency Control of Balanced/Unbalanced Distribution System Using the SMES System in the Presence of Wind Energy. Electricity 2021, 2, 205-224. https://doi.org/ 10.3390/electricity2020013

Academic Editor: Robert H. Lasseter

Received: 27 March 2021

Accepted: 24 May 2021

Published: 1 June 2021

Publisher's Note: MDPI stays neutral with regard to jurisdictional claims in published maps and institutional affiliations.

Copyright: (c) 2021 by the authors. Licensee MDPI, Basel, Switzerland. This article is an open access article distributed under the terms and conditions of the Creative Commons Attribution (CC BY) license (https:// creativecommons.org/licenses/by/ $4.0 /)$.

\begin{abstract}
This paper presents an effective solution to overcome the problem caused by intermittent energy sources that are connected to a balanced/unbalanced distribution system using a superconducting magnetic energy storage (SMES) system by mitigating the voltage and frequency fluctuations during wind gusts. The fuzzy logic control technique (FLC) is used with SMES to improve the voltage and frequency. A squirrel cage induction generator (SCIG) is applied as the wind energy generator. The IEEE 33-bus distribution system is used to validate the proposed method. Buses 18 33 are the weakest points in this system; thus, the wind and SMES systems are connected to the system at these buses. We used MATLAB/Simulink to simulate the performance of the IEEE 33-bus system (balanced/unbalanced) considering the SMES, wind system, and fuzzy logic control (FLC). The simulation results show the high performance of the proposed control method to alleviate the voltage and frequency fluctuation and achieve the power leveling strategy of the studied system.
\end{abstract}

Keywords: balanced/unbalanced distribution system; superconducting magnetic energy storage (SMES); wind energy; fuzzy logic controller (FLC); voltage control; frequency control

\section{Introduction}

Due to the significant benefits, such as the reduction of fossil fuel consumption and $\mathrm{CO}_{2}$ emissions, ensuring environmental cleanness, preserving rural areas, covering the load demand, and the long operation period, renewable energy sources (RESs) have become the favorable choice to generate electricity in many countries. The wind turbine is considered the lowest-cost RES; thus, it is utilized in most countries with different technologies. The penetration of RESs in general and wind turbines in particular has increased in many countries. According to the annual report [1], in 2019, the installed power capacity of RESs grew to more than 200 gigawatts, and the global wind power market expanded by $19 \%$ in 2019 to $60 \mathrm{GW}$ [1]. The doubly fed induction generator (Type 3) and full-rate converter wind turbines (Type 4) are considered the best wind generator types. However, the squirrel cage induction generator (SCIG, Type 1) is still used in the market [2] because it has many merits, such as low cost and high reliability. Moreover, some of the components that require continuous maintenance, such as the brushes, exciter, and slip rings, are not essential for an SCIG.

As is known, wind turbines depend on wind speed as the source for generation. The wind speed is unpredictable, leading to intermittent power generation from the wind turbine, which causes fluctuations in the voltage and frequency. Voltage and frequency stability are the most considerable problems that arise from balanced and unbalanced electrical networks. The frequency deviation degree shows the system's stability degree; meanwhile, preserving the voltage within the allowed limits keeps the operation satisfactory for the instrument and home appliances. 
Several methods have been proposed as a solution for the voltage and frequency issues, such as flexible alternating current transmission system (FACTS) devices [3-6] and the on-load tap changer (OLTC) [7]. Moreover, an adaptive coordinated voltage and frequency control scheme [8], an electronic load controller (ELC) [9], and intentional controlled islanding (ICI) [10] are also used. Reference [11] showed how to optimally locate and size distribution generators (DGs) into a radial distribution network before and after reconfiguration. Furthermore, a smart inverter improves the voltage unbalance index and detects the unbalanced state of voltage magnitude and phase [12] using energy storage systems (ESSs) $[13,14]$. A sensitivity-based voltage control strategy is developed for the energy storage system in [15]. ESSs are used for this purpose, which include a superconducting magnetic energy storage (SMES) unit $[16,17]$, a flywheel $[18,19]$, or batteries [20]. They are used as a vital solution for improving the stability of voltage and frequency during weather changes. To enhance the voltage and frequency fluctuations during wind gusts in both balanced and unbalanced distribution systems, the response time, efficiency, and lifetime are considered the most important factors when choosing ESSs. Today, the SMES unit is regarded as the best type.

An SMES unit has been used with a photovoltaic (PV) system in the presence of electric vehicles to enhance the power network [21,22], with wind/PV [23], and to improve the charging/discharging performance of electric vehicles [24]. In [25], the author used an SMES unit based on the adaptive fractional-order sliding-mode control approach to improve its dynamical responses against various operation conditions. The authors of [26] presented the control of a multi-level voltage source converter relying on SMES for effective support of the active and reactive power of an electrical power network, where the SMES unit is capable of supervising the electromechanical fluctuations instantly and aids in reducing the frequency deviations under the limits. The improvement of the electrical network's voltage and frequency stability during load insertion and rejection at constant wind speed with the help of an SMES with a fuzzy logic controller (FLC) is discussed considering a wind power-based permanent magnet synchronous generator (PMSG) in [27] and a double-fed induction generator simulation model (DFIG) in [28]. Two different architectures of high-temperature superconducting (HTS) power cables are investigated under AC conditions in [29]. The adaptive model predictive control is used with SMES to mitigate the various load frequency control issues in a multi-area power system [30]. An SMES unit has been installed on wind farms with small-scale wind speed variation to alleviate the frequency fluctuations [31]. It has also been used to regulate wind power at nominal wind speed [32]. The SMES system is applied to a wind system to stabilize the wind generator in [33]. An FLC-SMES has been proposed to improve the transient stability in a multi-machine power system [34]. In reference [16], the authors proposed a solution for the frequent changes in the operating current, transient thermal characteristics, and power exchange characteristics of SMES. Moreover, the self-inductance of the magnet and the effect of the critical current of the magnet during different operating conditions are presented in [35-39].

This paper proposes a control method based on FLC-SMES to mitigate the severe changes in the frequency, power, and voltage caused by wind gusts with $30 \%$ penetration of the total load connected to the IEEE 33-bus balanced/unbalanced distribution system for controlling the active and reactive power injected into the system. The SCIG is chosen in this case study because it represents the worst case of a wind system in the presence of wind gusts as a considerable variation to indicate the proposed control method's robustness. The SMES and wind turbines are connected at the weakest buses, i.e., buses 18 and 33. The control of active power is attained by a DC-DC chopper based on FLC control. The voltage source converter (VSC)-based proportional-integral (PI) controller performs the reactive power control. The SMES, wind turbine, IEEE 33-bus balanced/unbalanced distribution system, and FLC and PI controller were simulated using MATLAB software. The simulation results prove the efficacy of the proposed control method with SMES to alleviate the voltage and frequency fluctuation for the duration of wind gusts in balanced and unbalanced cases. 


\section{The Main Contributions}

The main contributions of this paper are as follows:

- It proposes a control method to alleviate frequency and voltage fluctuations in a balanced/unbalanced distribution system connected to high wind power penetration during wind gusts.

- It achieves a power leveling strategy during wind gusts.

- The FLC technique is proposed for a DC-DC chopper to define the charging/discharging process of the SMES system.

- It designs a bi-directional VSC based on a PI controller to achieve reactive power support of the main grid.

- It smooths the real power output during wind gusts.

The rest of this paper is organized as follows: Section 2 shows the overall system mode, Section 3 presents the proposed control technique of SMES, Section 4 presents and discusses the simulation results, and Section 5 offers the conclusions.

\section{System Model}

\subsection{System Configuration}

Figure 1 shows the studied system used as a case study, consisting of a 33-bus system connected to the grid as the primary power source. The wind turbine and the SMES systems are connected at buses 18 and 33, because these buses represent the weakest points from the voltage profile point of view [40].

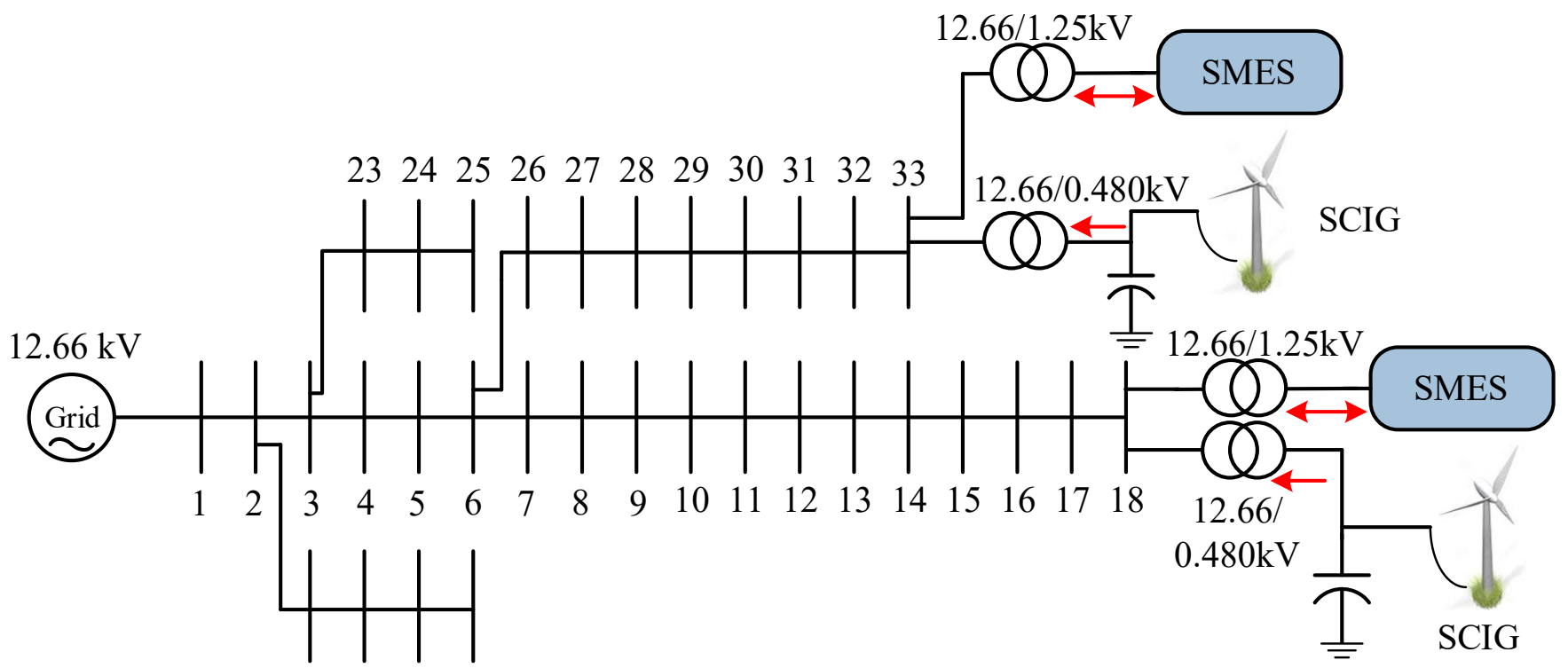

19202122

Figure 1. The 33-bus radial distribution system as a test system.

The data of the lines and buses are found in [41]. Table 1 presents the data of the SCIG system and the SMES system that will be discussed in the below sections.

Table 1. The system parameter.

\begin{tabular}{ccc}
\hline Parameter & Unit & Value \\
\hline System RMS voltage & $\mathrm{kV}$ & 12.66 \\
\hline System frequency & $\mathrm{Hz}$ & 50 \\
\hline
\end{tabular}


Table 1. Cont.

\begin{tabular}{ccc}
\hline Parameter & Unit & Value \\
\hline Power rating & SCIG system & \\
\hline RMS voltage & MVA & $0.6 / 0.9$ \\
\hline Resistance of stator, $R_{s}$ & $\mathrm{~V}$ & 480 \\
\hline Reactance of stator, $X_{S}$ & $\mathrm{pu}$ & 0.01965 \\
\hline Resistance of rotor, $R_{r}$ & $\mathrm{pu}$ & 0.0397 \\
\hline Reactance of rotor, $X_{r}$ & $\mathrm{pu}$ & 0.01909 \\
\hline Magnetizing reactance, $X_{m}$ & $\mathrm{pu}$ & 0.0397 \\
\hline & $\mathrm{pu}$ & 1.354 \\
\hline SMES energy, $E_{S M E S}$ & SMES system & 1.0 \\
\hline SMES coil inductance, $L_{S M E S}$ & $\mathrm{MJ}$ & 0.5 \\
\hline SMES current, $I_{S M E S}$ & $\mathrm{H}$ & 2000 \\
\hline DC-bus LINK voltage, $V_{d c-l i n k}$ & $\mathrm{~A}$ & 2400 \\
\hline DC-bus capacitance, $C_{d c-l i n k}$ & $\mathrm{~V}$ & 10 \\
\hline
\end{tabular}

\subsection{Wind System Model}

The SCIG is used as a generator with a wind turbine system. The capacitor bank is linked to the SCIG to inject reactive power and improve the power factor. The mechanical output power of the generator can be computed from Equation (1) [42]. The equivalent circuit of the SCIG and the related equation of the model are presented in $[28,43]$.

$$
P_{m}=0.5 C_{P}(\lambda, \beta) \rho A v_{\text {wind }}^{3}
$$

where $A$ is the turbine area, $\rho$ is the air density, $v$ is wind speed, $C_{P}$ is the coefficient performance of the turbine.

The $C_{P}$ depends on the tip speed ratio $(\lambda)$ and blade pitch angle $(\beta)$. The $C_{P}$ of SCIG can be calculated from Equations (2) and (3) [44].

$$
\begin{gathered}
C_{P}(\lambda, \beta)=C_{1}\left(\frac{C_{2}}{\lambda_{i}}-C_{3} \beta-C_{4}\right) e^{-\frac{C_{5}}{\lambda_{i}}}+C_{6} \lambda_{i} \\
\frac{1}{\lambda_{i}}=\frac{1}{\lambda+0.08 \beta}-\frac{0.035}{\beta^{3}+1}
\end{gathered}
$$

where $C_{P}$ is the coefficient performance of the turbine, $\lambda$ is the tip speed ratio, $\beta$ is the blade pitch angle, and the values of the coefficients $C_{1}$ to $C_{6}$ are $0.5176,116,0.4,5,21$, 0.0068, respectively.

\subsection{SMES Model}

The SMES unit is a type of RES that depends on storing the energy in magnetic form. Figure 2 presents the SMES system's main components: the protection system, the cryogenic refrigerator, the cryostat/vacuum vessel to preserve the coil in the superconductivity state, the superconducting coil, and the power conditioning system, which has two parts-the VSC and the DC-DC chopper. The SMES energy $\left(E_{\text {smes }}\right)$ and SMES power $\left(P_{\text {smes }}\right)$ can be calculated from Equations (4) and (5) by considering the SMES current $\left(I_{s m e s}\right)$ and inductance $\left(L_{\text {smes }}\right)$. 


$$
\begin{gathered}
E_{\text {smes }}=\frac{1}{2} L_{\text {smes }} I_{\text {smes }}^{2} \\
P_{\text {smes }}=\frac{d E_{\text {smes }}}{d t}=L_{\text {smes }} I_{\text {smes }} \frac{d I_{\text {smes }}}{d t}=V_{\text {smes }} I_{\text {smes }}
\end{gathered}
$$

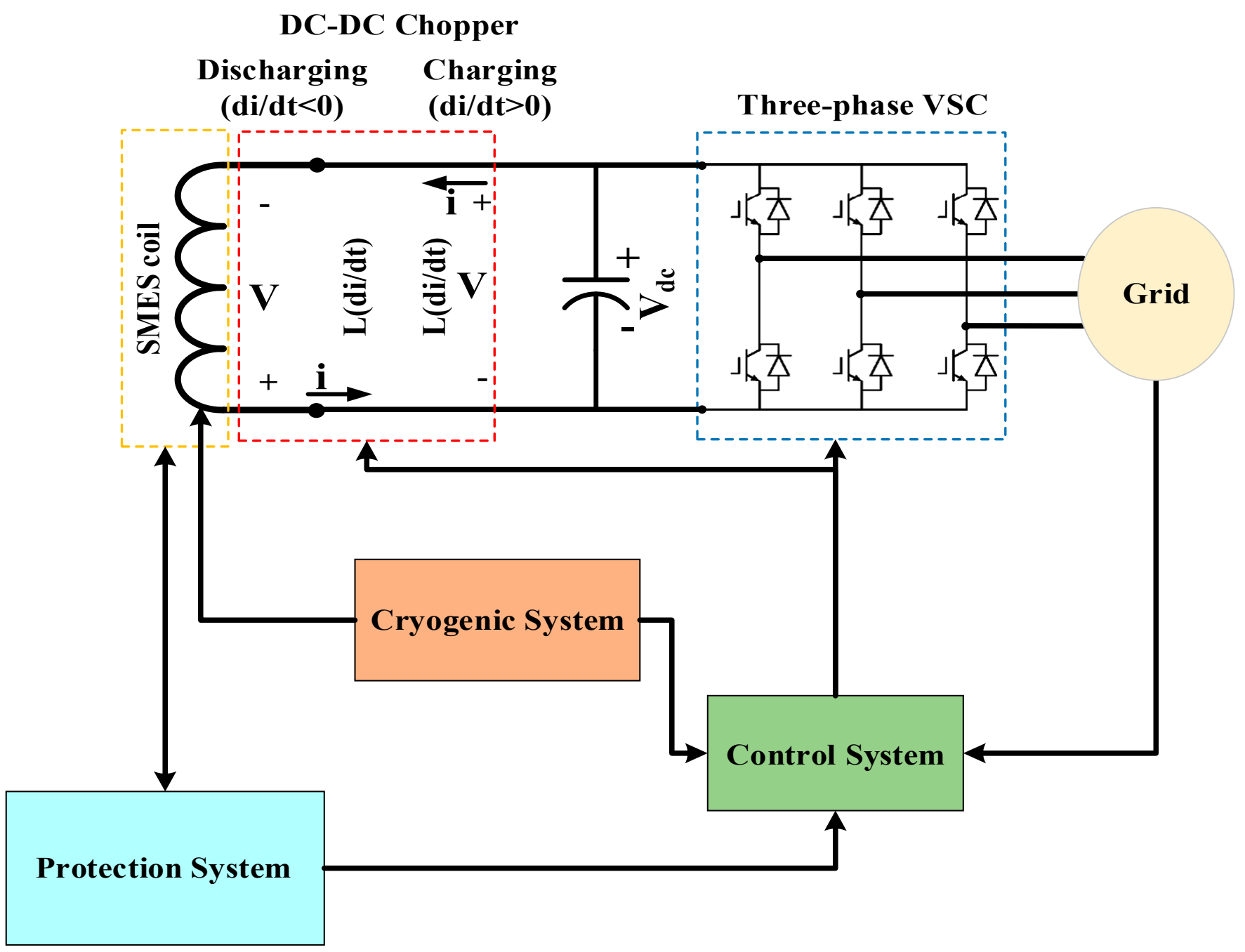

Figure 2. The SMES system configuration.

\section{The Proposed Control Technique of SMES}

Figure 3 depicts the overall control of the SMES, which has two key phases. The first phase is the bidirectional VSC to control the injected/absorbed reactive power to/from the grid by the SMES unit. The control of VSC depends on the PI controller, and the modeling framework of voltage-source converters is presented in [45,46]. The second phase is the DC-DC chopper, which controls the active power injected/absorbed to/from the grid by the SMES unit. The FLC is used with SMES to carry out the charging and discharging process. The FLC has two inputs and one output. The first input $\left(d_{V w i n d}\right)$ is the difference between the actual wind speed and the nominal wind speed; the second input $\left(d_{\text {Ismes }}\right)$ is the difference between the SMES actual current and its reference value. The output is the duty cycle $(D)$ compared with high switching frequency to fire the DC-DC chopper switches. 
Thus, the SMES DC-DC has three modes, as shown in Figure 3. The first mode is the charging mode; when the $D$ achieves the condition $0.5<D \leq 1$, a positive voltage appears across the coil of the SMES. The second mode is the standby mode, when the voltage across the coil is zero and $D=0.5$. The third mode is the discharging mode; a negative voltage appears across the SMES coil and $0 \leq D<0.5$. The variables of FLC each have five sets of membership functions (MFs). IF-AND-THEN are used to transform the rules of the fuzzy control into crisp control actions. The overall proposed control of the DC-DC chopper is shown in Figure 4 . The first input $\left(d_{V w i n d}\right)$ and the second input $\left(d_{\text {Ismes }}\right)$ have five sets of MFs (NL = Negative Large, NS = Negative Small, Z = Zero, PS = Positive Small, $\mathrm{PL}=$ Positive Large); meanwhile, the output (D) has five sets of MFs (DL = Discharge Large, DS = Discharge Small, NOA = No Action, $C S=$ Charge Small, $\mathrm{CL}=$ Charge Large) .

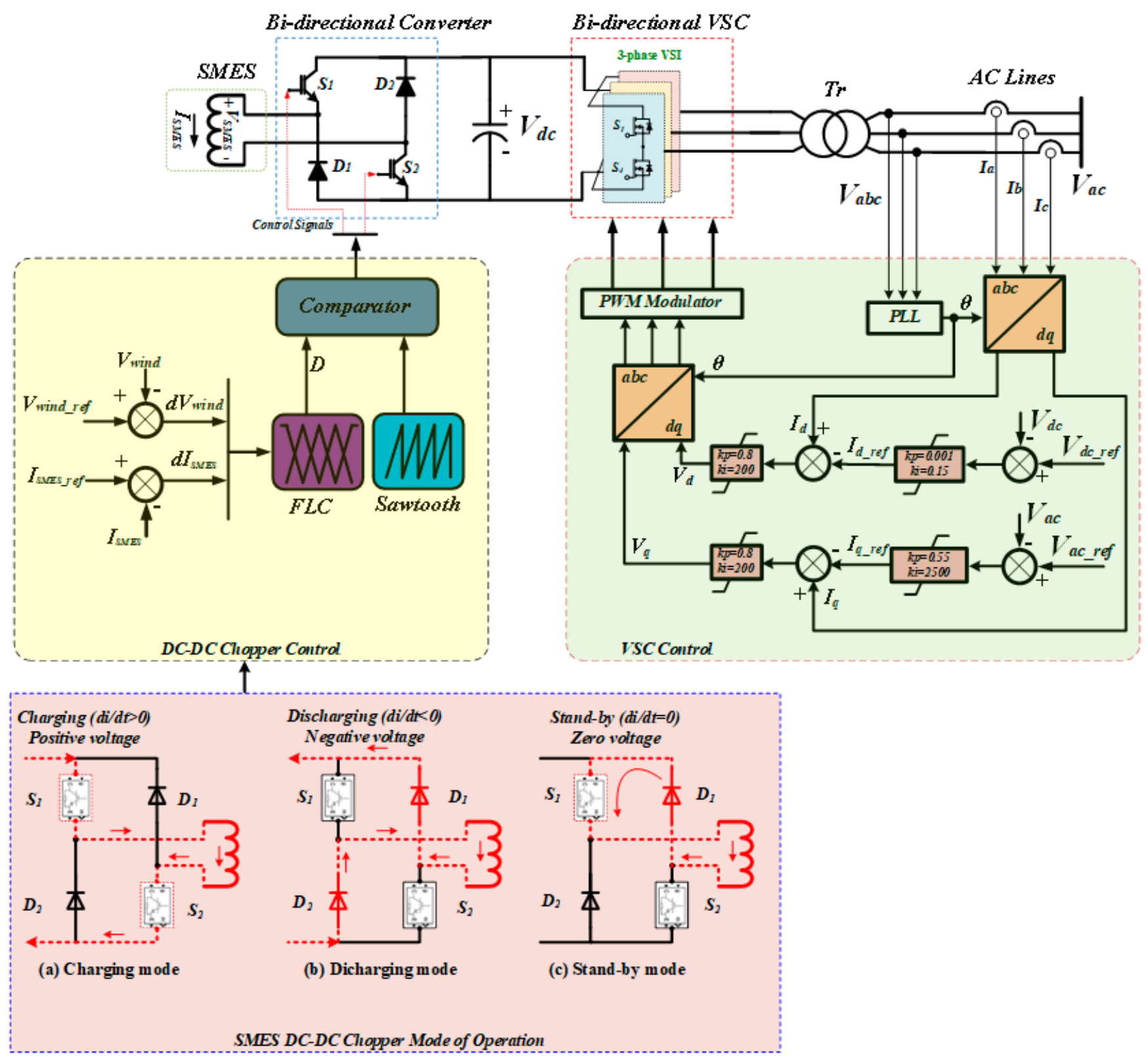

Figure 3. The overall proposed control system. 


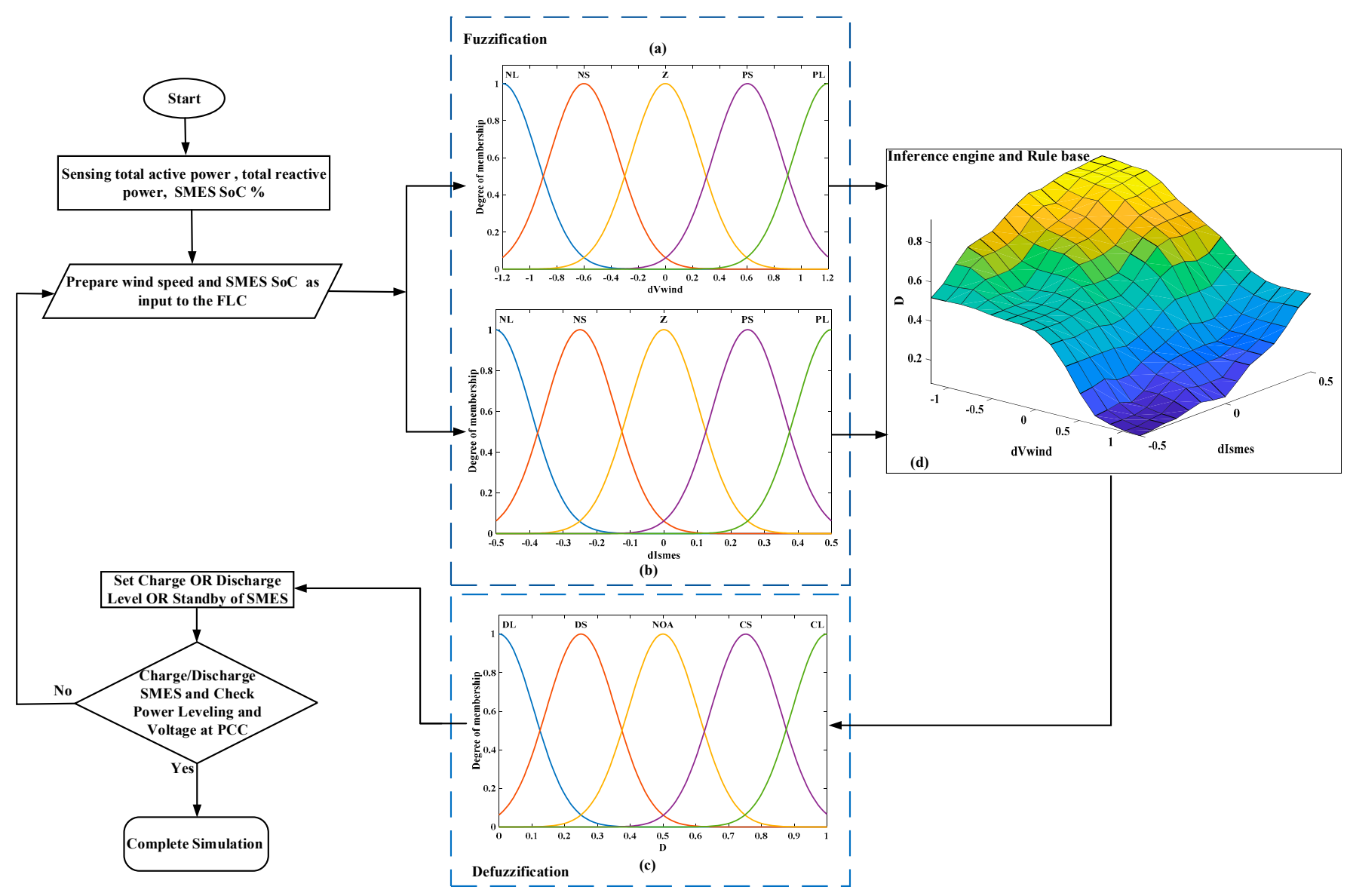

Figure 4. The proposed control system of the DC-DC chopper based on FLC.

\section{Simulation Results and Discussion}

The proposed FLC-SMES is examined in the balanced and unbalanced cases to improve the IEEE 33-bus distribution system's voltage and frequency and achieve the power leveling of the wind system in the presence of wind-based SCIG during wind gusts, as shown in Figure 5.

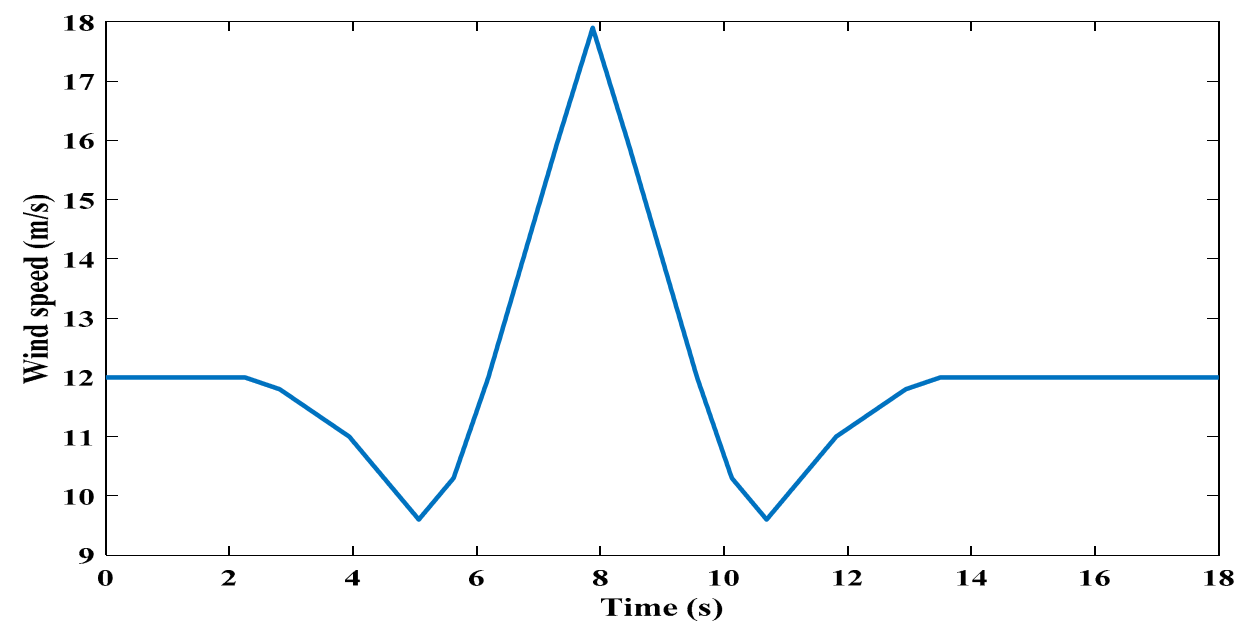

Figure 5. Wind gust. 


\subsection{Balanced Case}

In this section, the performance of the IEEE 33-bus balanced distribution system will be discussed. The voltages at buses 18 and 33 are displayed in Figure $6 a, b$, respectively. The voltage in the SMES case at buses 18 and 33 is improved and maintained within the acceptable levels. At bus 18, the voltage is enhanced from less than $0.94 \mathrm{pu}$ to around $1.02 \mathrm{pu}$, and at bus 33, from less than $0.94 \mathrm{pu}$ to $1.0 \mathrm{pu}$. In addition to the voltage improvement, the frequency fluctuations are mitigated successfully by utilizing the SMES system with its controller, as shown in Figure 7.

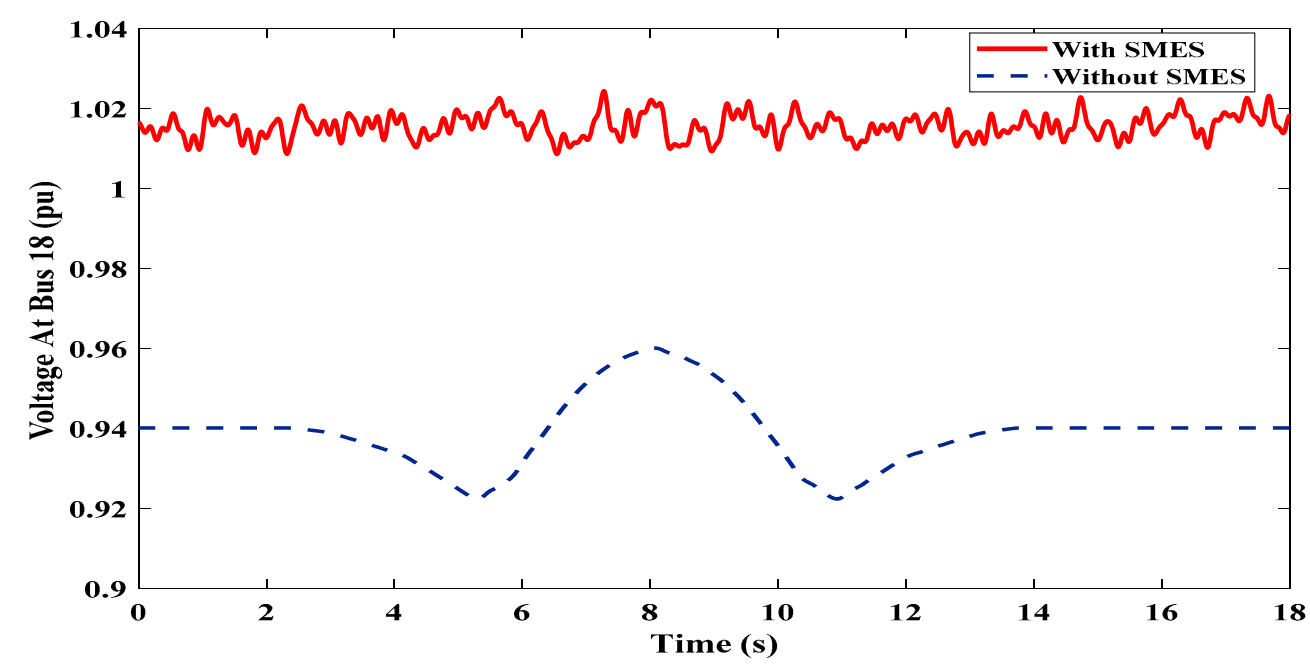

(a)

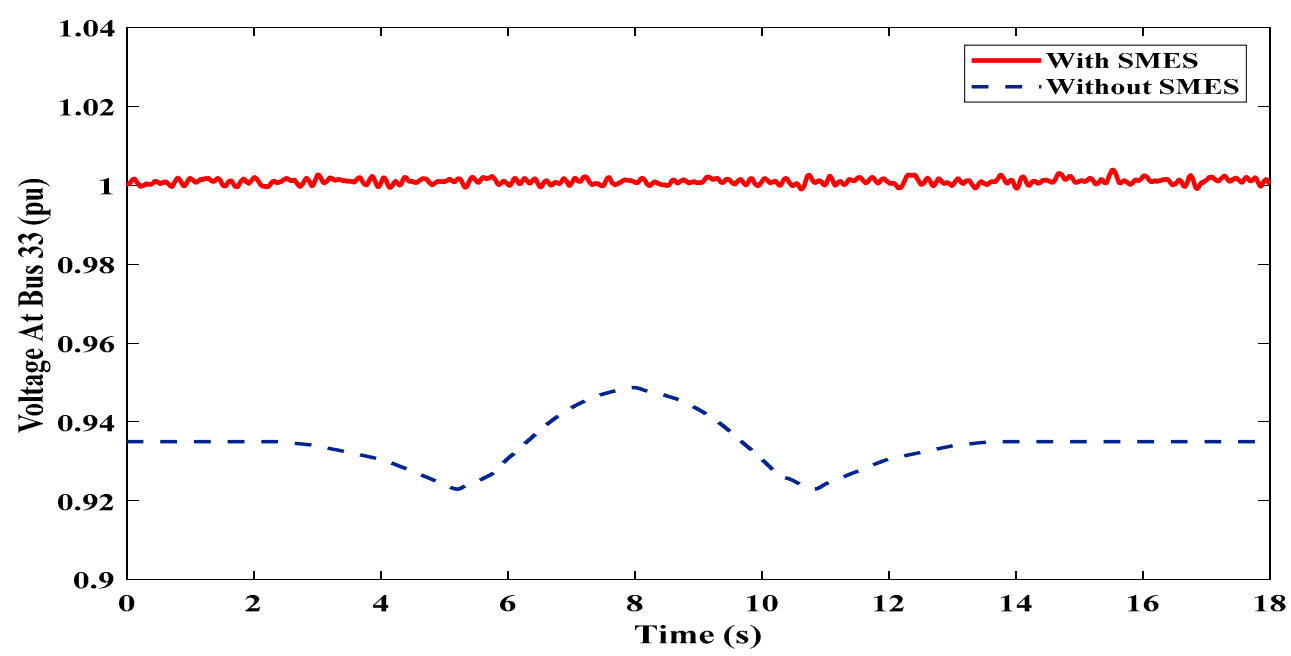

(b)

Figure 6. The voltage response for balanced case: (a) bus 18 (b) bus 33 .

The powers injected at bus 18 and 33, as shown in Figure 8a,b, are smoothed successfully, where the proposed SMES-FLC achieves the power leveling strategy to improve the system's stability. Moreover, the power injected from the grid is minimized and smoothed as a reason for charging (positive sign) and discharging power (negative sign) from the SMES, as shown in Figures 9 and 10. 


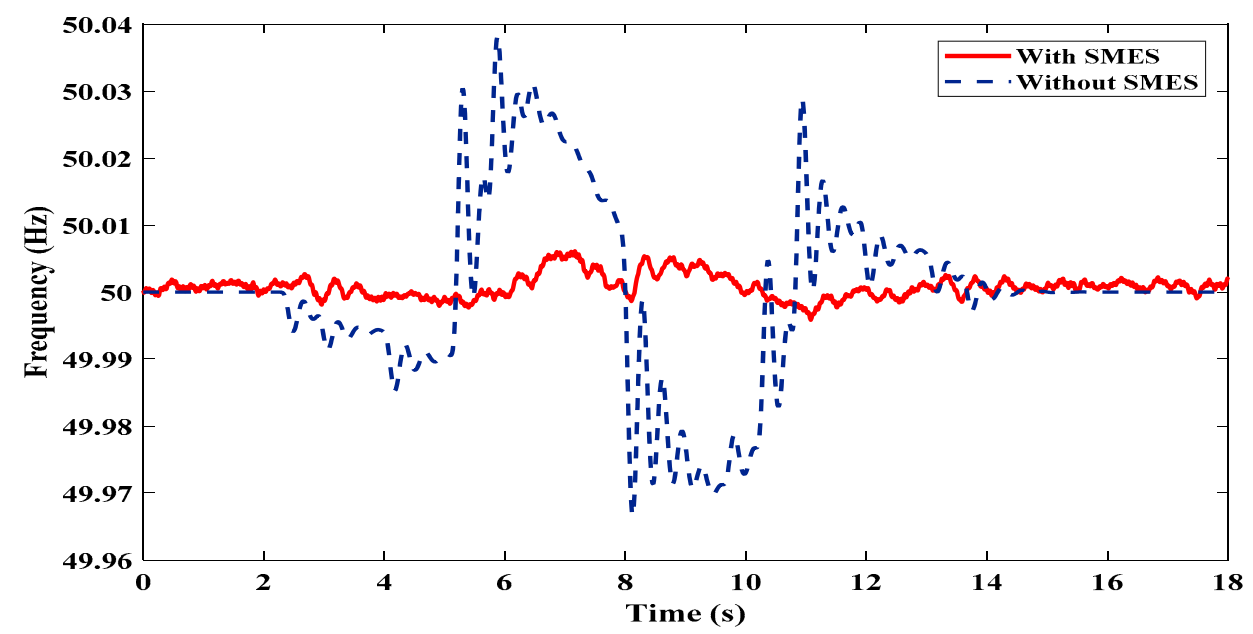

Figure 7. The frequency response in a balanced case.

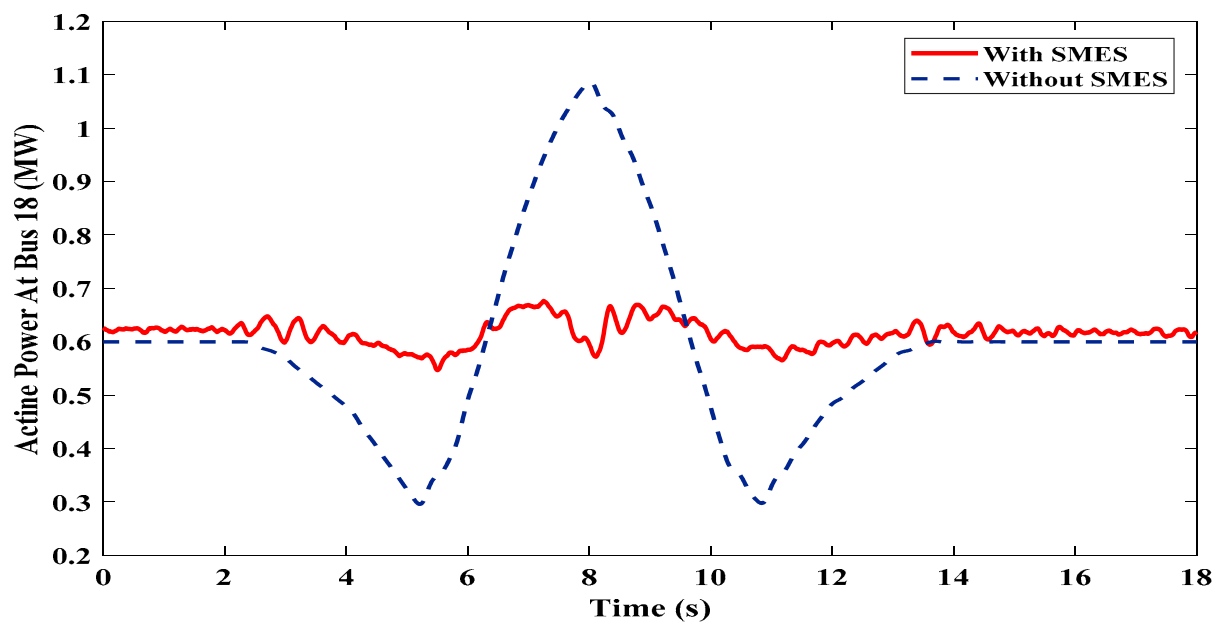

(a)

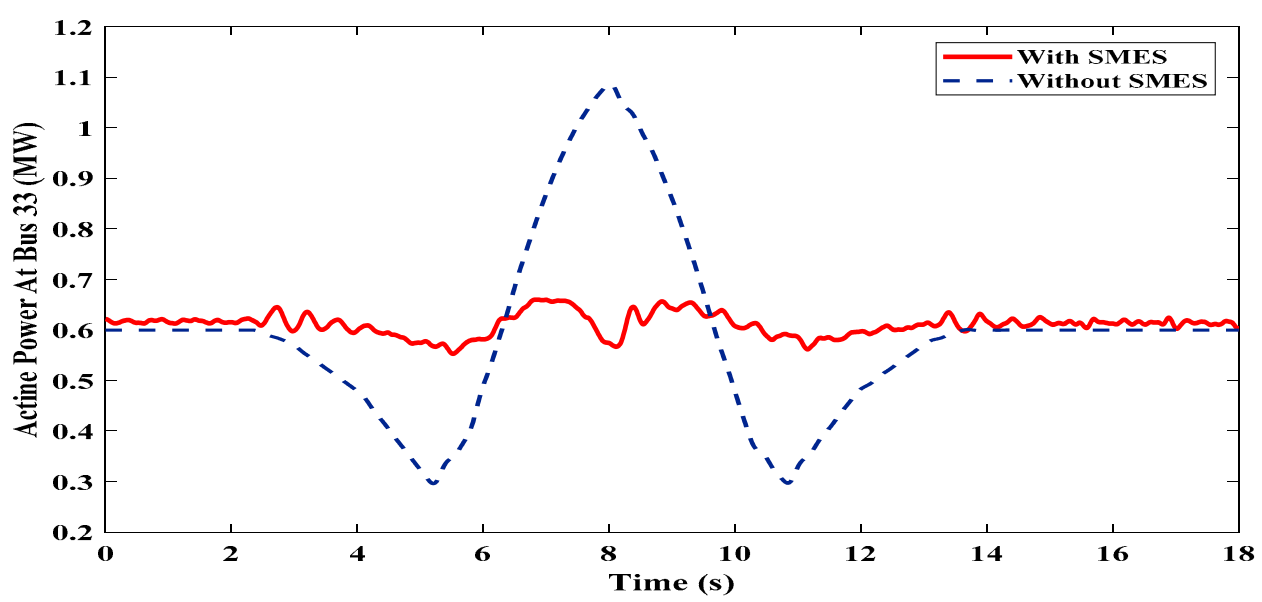

(b)

Figure 8. The active power injected at (a) bus 18, (b) bus 33 . 


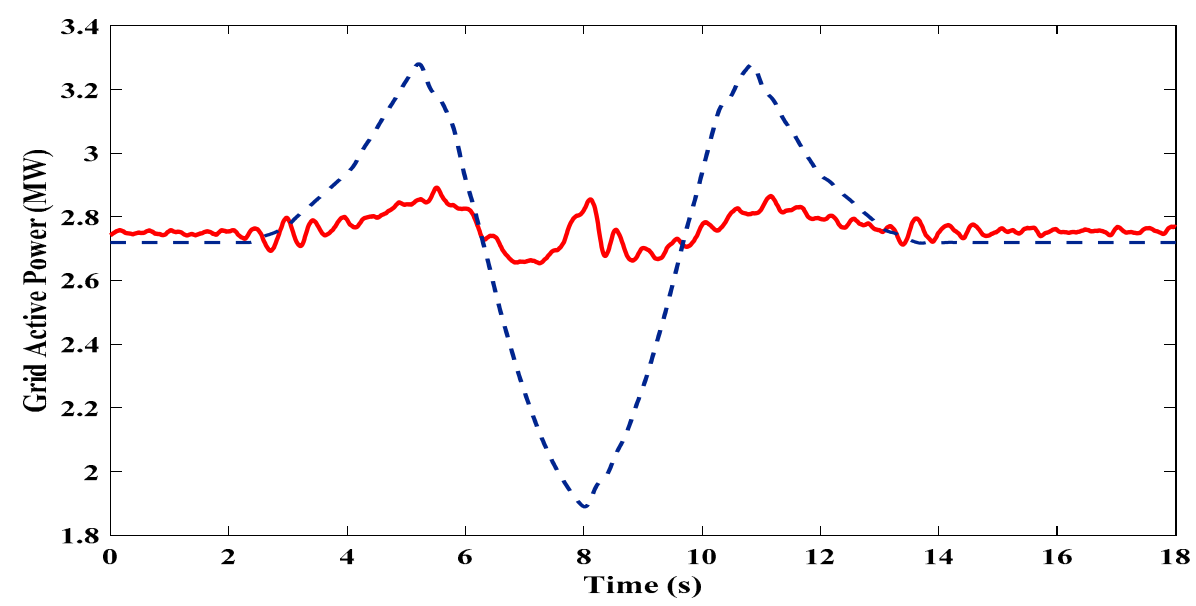

Figure 9. The grid active power.

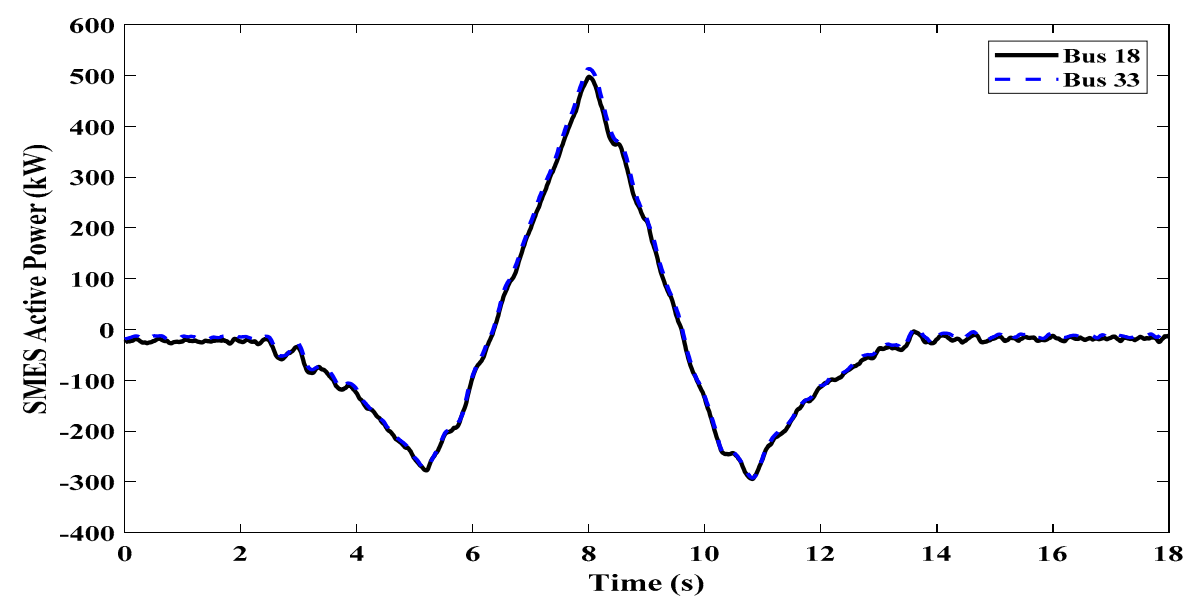

Figure 10. The SMES active power.

The grid reactive power is reduced, as shown in Figure 11, because the SMES injects reactive power into the grid and wind system, as shown in Figure 12, which helps to improve the power factor and grid performance. The operational characteristics of SMES are shown in Figures 13-15. Figures 13 and 14 present the charging and discharging operation of SMES during wind speed gusts. Figure 15 shows the DC-bus voltage, which is constant during the overall time and validates the control system process.

Table 2 lists the numerical results of the balanced case with and without FLC-SMES. Voltage values during the wind gust at bus 18 and 33 are improved when the SMES system is activated. When the wind speed is lower than the nominal value, the voltage at bus 18 reaches $0.922 \mathrm{pu}$ without SMES and 1.01 with SMES; the voltage at bus 33 reaches $0.923 \mathrm{pu}$ if the SMES is deactivated, and 1.001 if the SMES is activated. However, when the wind speed is more than the nominal value, the voltage response at bus 18 and 33 reaches 0.960 and 0.948 , respectively, without the SMES system. Meanwhile, in the presence of an SMES, the voltage response at bus 18 and 33 reaches 1.024 and 1.004, respectively. The SMES system has the ability to support the grid by reactive power to mitigate the voltage fluctuation during wind gusts; the reactive power control is utilized with VSC based on a PI controller. Therefore, the SMES supported the grid by reactive power of around 0.4 MVAR at bus 18 and 1.85 MVAR at bus 33. Consequently, the maximum value of reactive power supplied from the grid is reduced from 3.75 MVAR (without SMES case) to 1.00 MVAR (with SMES case). Furthermore, the minimum value of grid reactive power is reduced from 2.95 MVAR (without SMES case) to 0.75 MVAR. Besides supporting the grid by reactive power, the SMES system is able to inject active power into the grid during low wind speed and absorb active power during high wind speed. This helps to achieve the power leveling 
strategy for bus 18 and 33 and for the grid. The difference between the maximum and minimum value of active power at bus 18 and bus 33 is $0.4 \mathrm{MW}$ without the SMES system and $0.03 \mathrm{MW}$ with the SMES system. At the grid, the difference between the maximum and minimum value of active power reached $0.23 \mathrm{MW}$ (with SMES case), instead of 1.4 MW (without SMES case). This, in turn, led to an improvement in the frequency response, where the maximum value was minimized from $50.038 \mathrm{~Hz}$ to $50.005 \mathrm{~Hz}$, and the minimum value was minimized from $49.965 \mathrm{~Hz}$ to $50.00 \mathrm{~Hz}$. Moreover, the number of oscillation cycles was reduced.

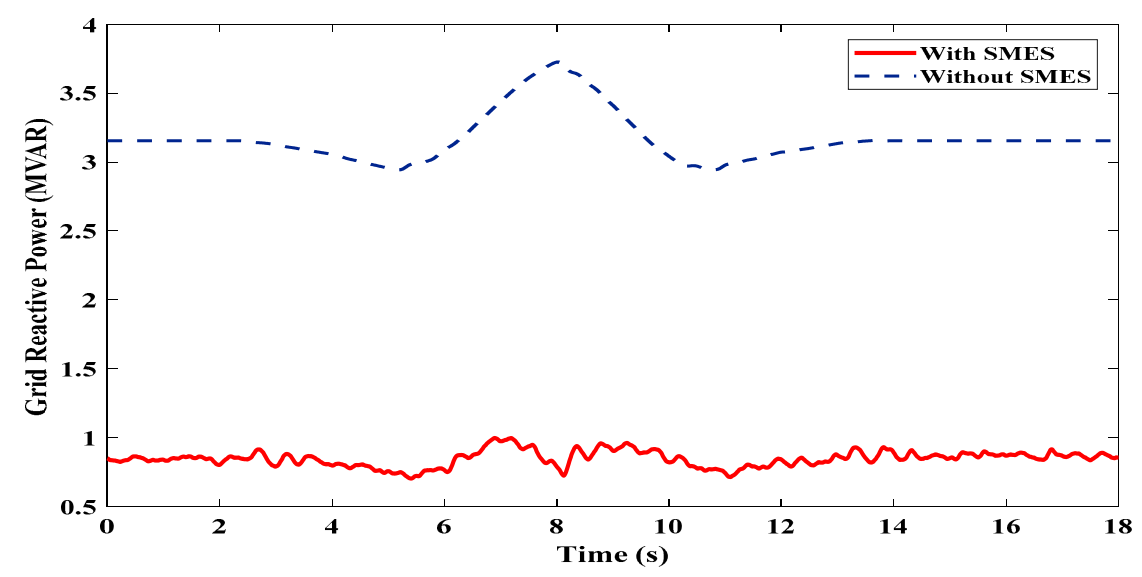

Figure 11. The grid reactive power.

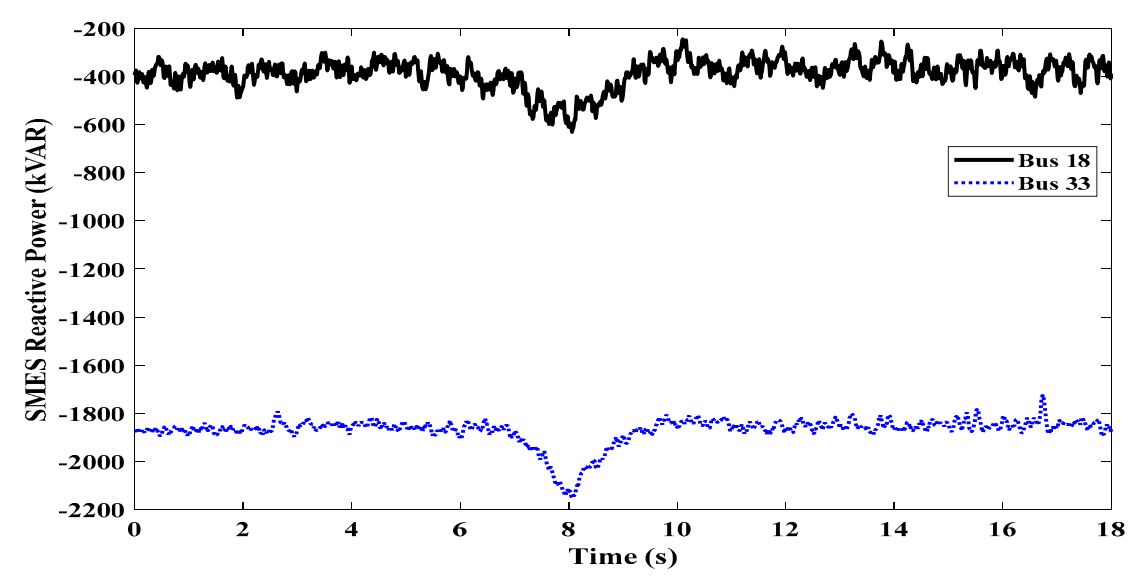

Figure 12. The SMES reactive power.

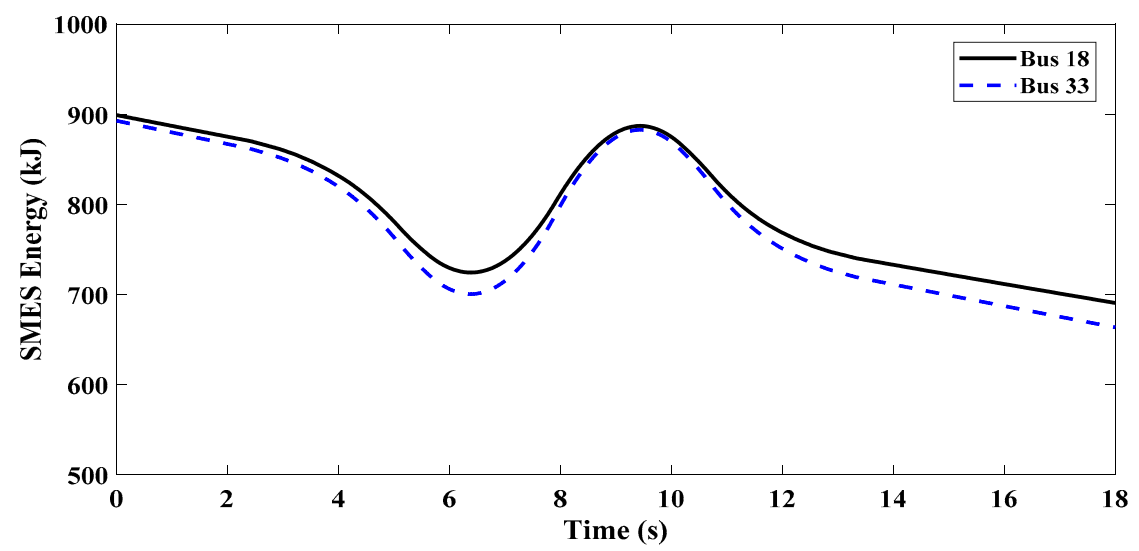

Figure 13. The SMES energy. 


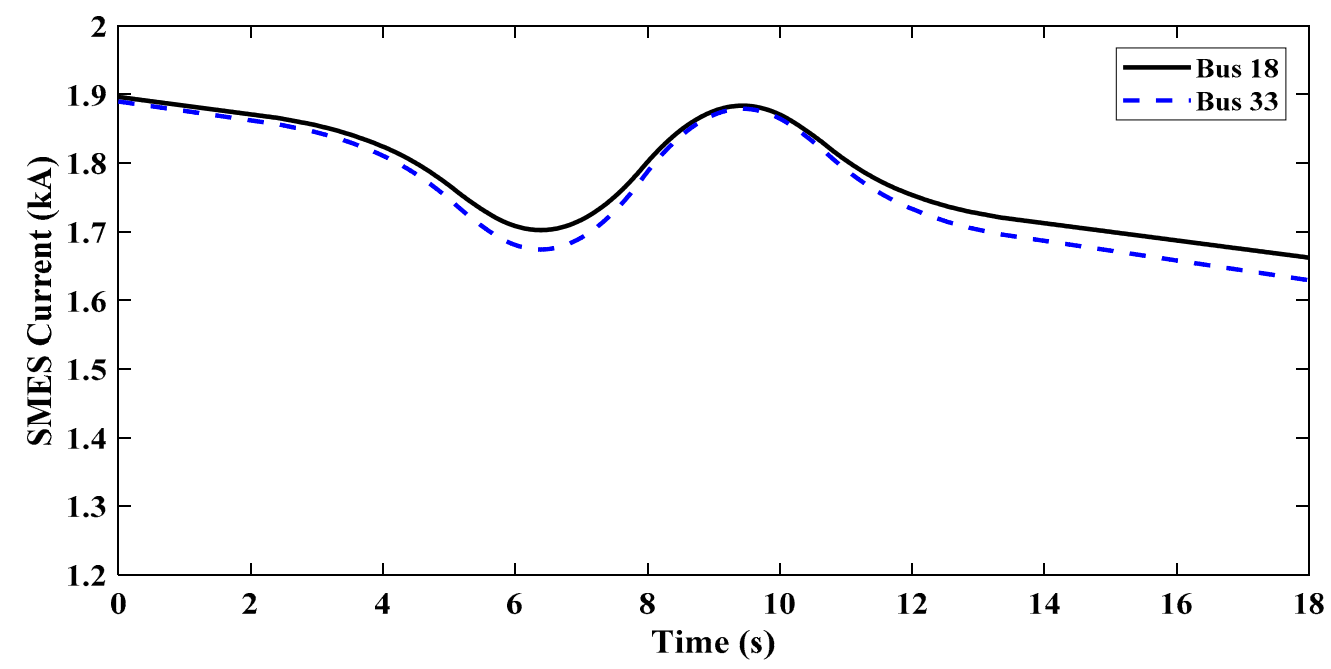

Figure 14. The SMES current.

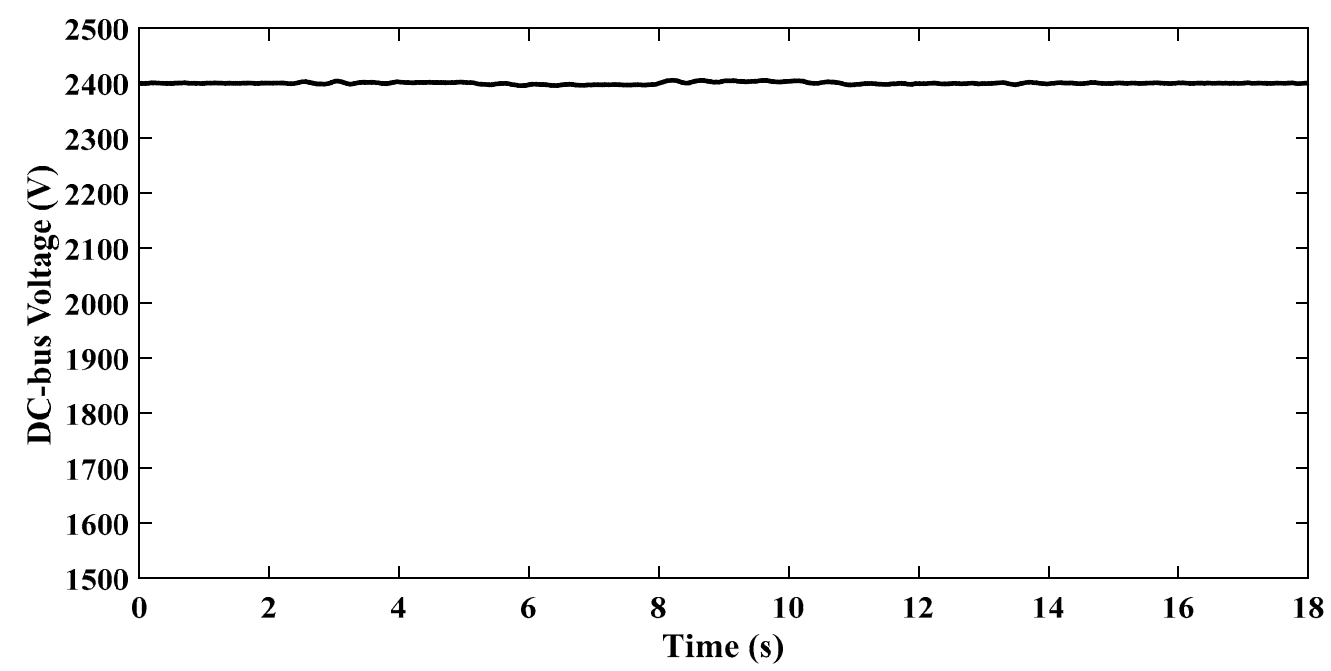

Figure 15. The DC-bus voltage.

Table 2. The numerical results of the balanced case.

\begin{tabular}{ccccc}
\hline & \multicolumn{2}{c}{ Without SMES } & \multicolumn{2}{c}{ With SMES } \\
\cline { 2 - 5 } & Maximum & Minimum & Maximum & Minimum \\
\hline Voltage at bus 18 $(\mathrm{pu})$ & 0.960 & 0.922 & 1.024 & 1.010 \\
\hline Voltage at bus 33 $(\mathrm{pu})$ & 0.948 & 0.923 & 1.004 & 1.001 \\
\hline Frequency $(\mathrm{Hz})$ & 50.038 & 49.965 & 50.005 & 50.000 \\
\hline Active power at 18 $(\mathrm{MW})$ & 0.650 & 0.250 & 0.420 & 0.390 \\
\hline Active power at 33 $(\mathrm{MW})$ & 0.650 & 0.250 & 0.420 & 0.390 \\
\hline Grid active power $(\mathrm{MW})$ & 3.300 & 1.900 & 2.890 & 2.660 \\
\hline Grid reactive power (MVAR) & 3.750 & 2.950 & 1.000 & 0.750 \\
\hline
\end{tabular}

\subsection{Unbalanced Case}

The proposed control method is verified by the unbalanced case, where the loads are divided between three phases, a, b, and c, by 30\%, 20\%, and 50\% of the total load, respectively. In this case, the voltage responses of phases $a, b$, and $c$ are improved. Phase $c$ is considered to have the largest load value, so the voltage of phase $c$ is the worst one. The 
voltage responses at buses 18 and 33 for the three phases are illustrated in Figure 16a,b; all the phases at buses 18 and 33 successfully remained within the limits during the presence of the SMES system, which led to the maintenance of the stability of the electrical power system. The frequency fluctuations were also damped in the unbalanced case in the SMES system's presence, as shown in Figure 17. This, in turn, improved the power system's stability during the wind speed gust in the case of an unbalanced load. The power system becomes more reliable and stable as a result of voltage and frequency control using FLC-SMES.

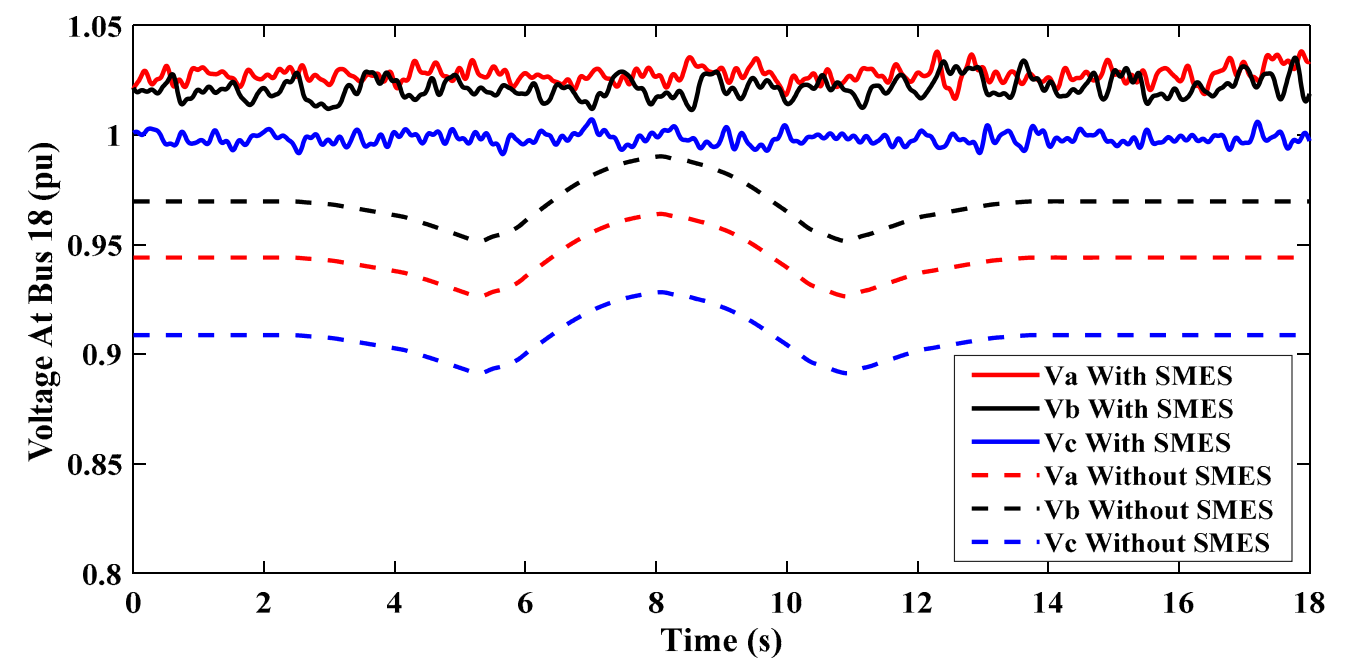

(a)

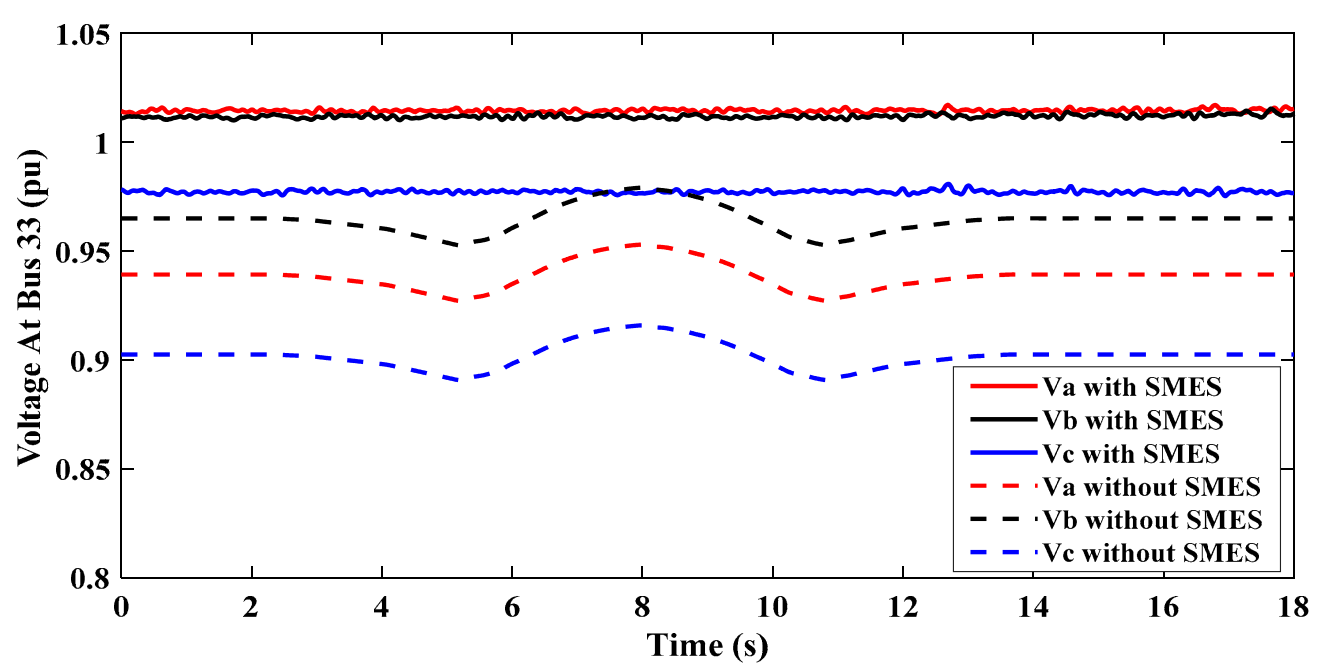

(b)

Figure 16. The voltage response in the unbalanced case: (a) bus 18, (b) bus 33 .

The presence of SMES with its controller at bus 18 and 33 ensured power leveling at these buses, as displayed in Figure 18a,b, respectively; meanwhile, without SMES, the active power fluctuates between $0.25 \mathrm{MW}$ and $0.65 \mathrm{MW}$. Meanwhile, in the case of using SMES, this value is around 0.4 MW. This strategy has a positive impact on the grid, as the active power supported in the system by the grid has a smooth response, as indicated in Figure 19. The injected power fluctuates from 1.9 MW to 3.3 MW in the case without an SMES. When the SMES is activated, the grid active power fluctuates between $2.7 \mathrm{MW}$ and 2.9 MW. The reduction in the injected active power from the grid results from using the SMES, where the SMES injects active power into the grid, as presented in Figure 20. The 
negative sign indicates the discharging mode of SMES, and the power is absorbed from the grid during high wind speed variation. The positive sign indicates the charging mode of the SMES, and the active power is injected into the grid during low wind speed variation.

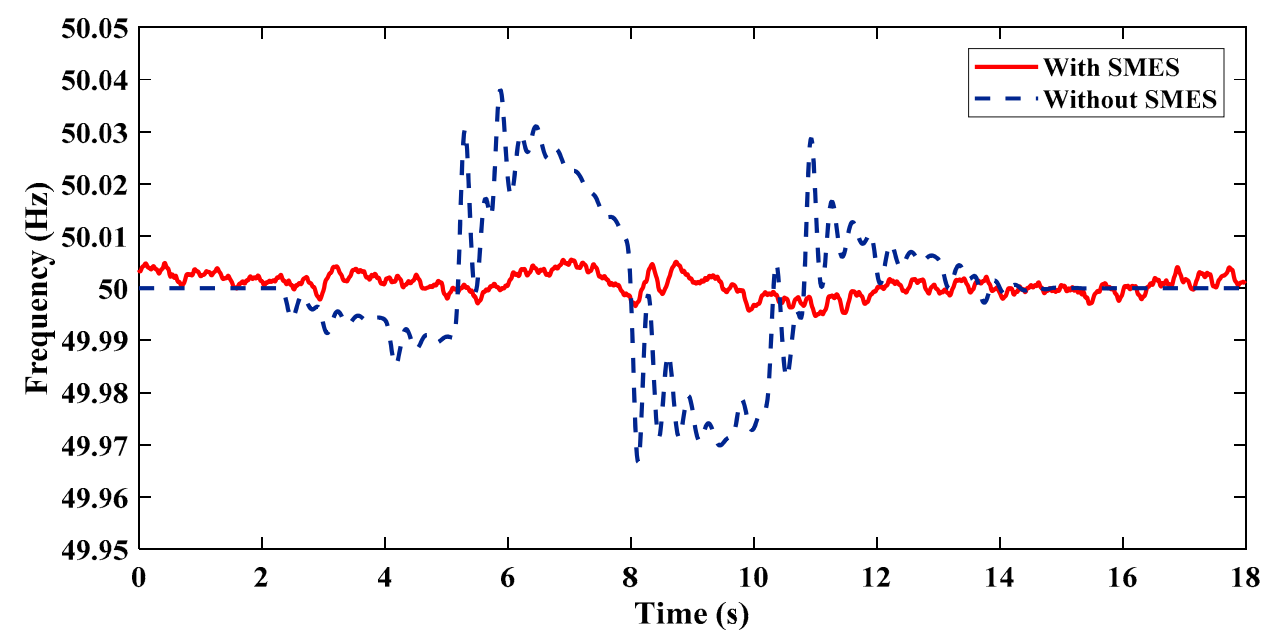

Figure 17. The system frequency in the unbalanced case.

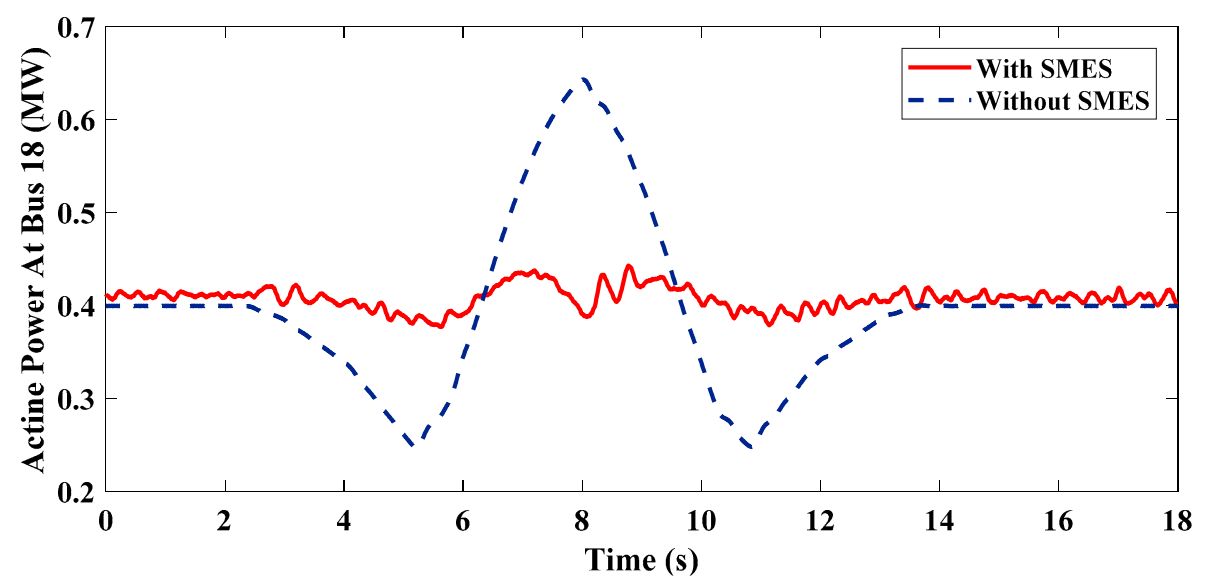

(a)

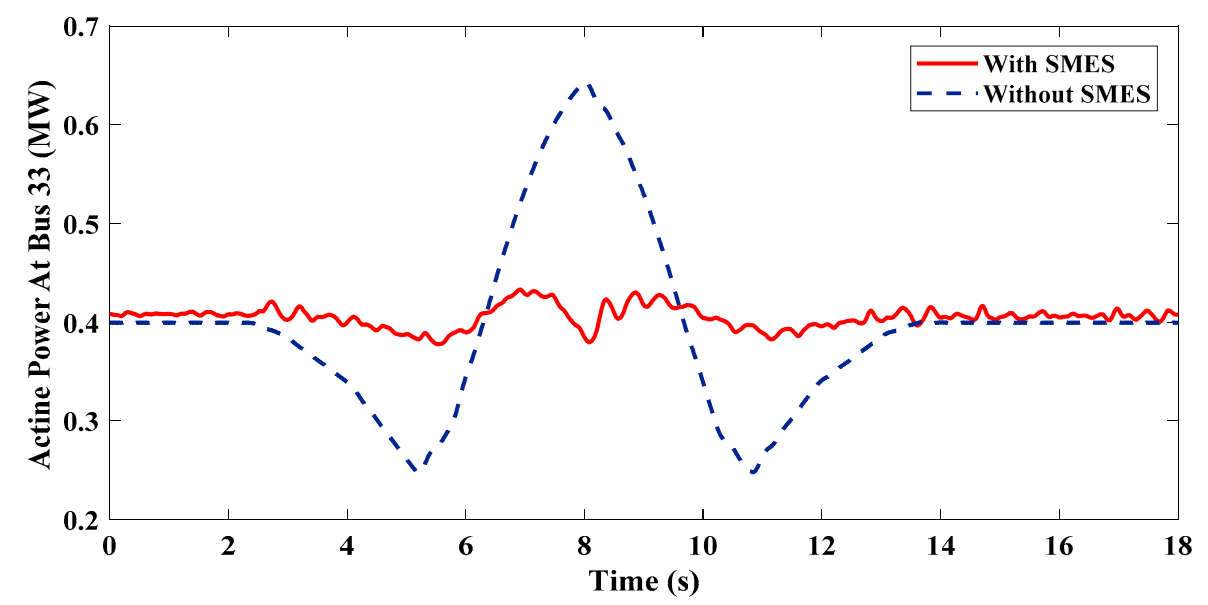

(b)

Figure 18. The active power injected at (a) bus 18, (b) bus 33 . 


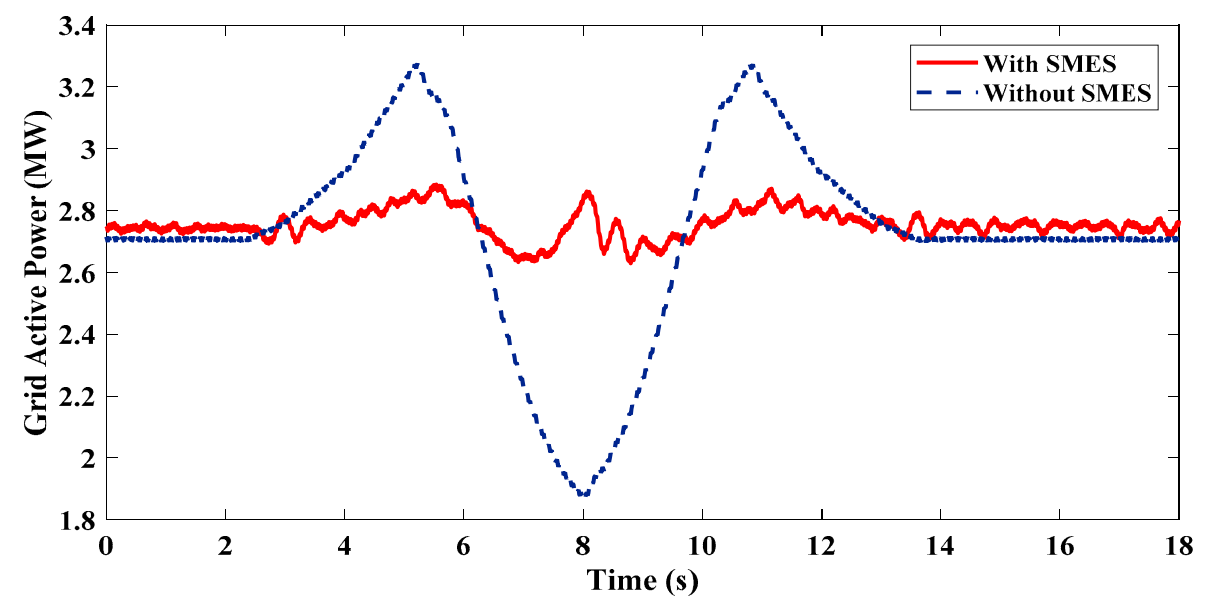

Figure 19. The grid active power.

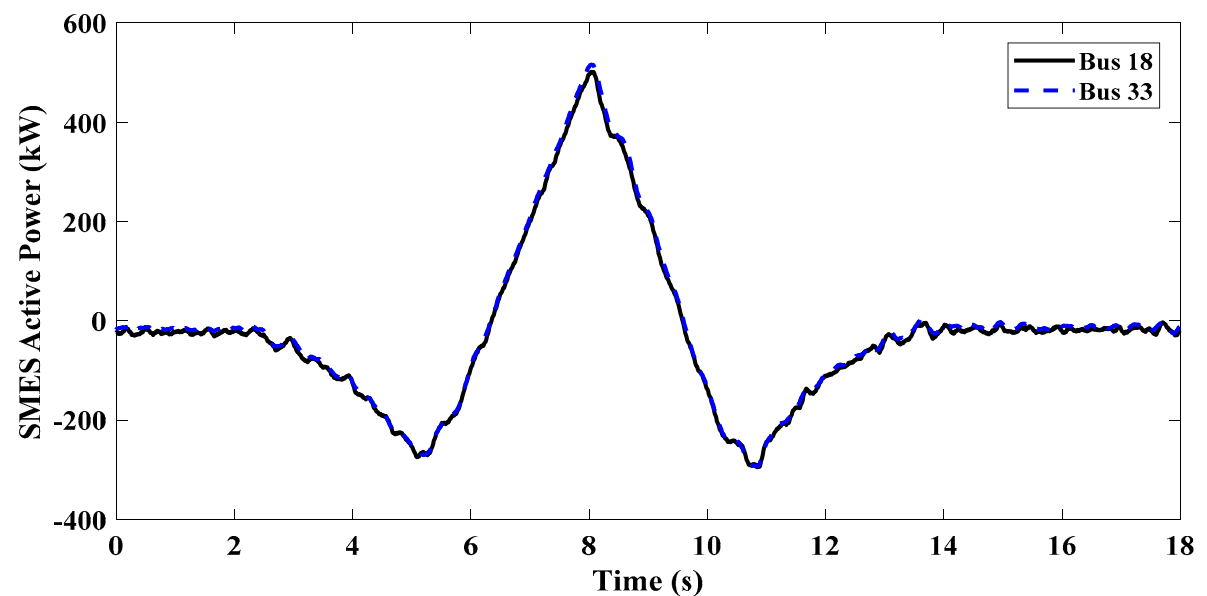

Figure 20. The SMES active power.

According to the voltage, control is applied by using the VSC, based on the PI controller. The voltage response of the three phases is improved. This is achieved because the reactive power supplied by the grid is reduced, as shown in Figure 21. The reactive power injected from the grid is around 3.7 MVAR, while, when using SMES, the grid reactive power reaches approximately 0.8 MVAR. The SMES injects reactive power into the grid, as presented in Figure 22, to improve the voltage response, and the reduction in reactive power absorbed from the grid leads to an improvement in the power factor. The SMES energy and SMES current are displayed in Figures 23 and 24, respectively, which indicate the mode of SMES operation. To prove the effectiveness of the proposed control method, the voltage of the DC-bus is kept constant during the wind speed gust, as presented in Figure 25.

The numerical results of the unbalanced case with and without FLC-SMES are shown in Table 3. Here, the reactive power control based on PI-VSC is successful in ensuring the control and improvement of the voltage. When the SMES is energized, the maximum and minimum value of reactive power supplied by the grid is minimized from 3.750 MVAR to 1.020 MVAR and from 2.950 MVAR to 0.670 MVAR, respectively. Accordingly, the unbalanced three-phase voltages experience an enhancement; at bus 18 , the voltage minimum value of phase $\mathrm{a}, \mathrm{b}$, and $\mathrm{c}$ is improved from $0.950 \mathrm{pu}, 0.920 \mathrm{pu}$, and $0.890 \mathrm{pu}$ to $1.019 \mathrm{pu}$, $1.012 \mathrm{pu}$, and $0.993 \mathrm{pu}$, respectively, when the SMES is turned on. At bus 33, the voltage minimum value of phase $\mathrm{a}, \mathrm{b}$, and $\mathrm{c}$ is improved from $0.950 \mathrm{pu}, 0.927 \mathrm{pu}$, and $0.890 \mathrm{pu}$ to $1.017 \mathrm{pu}, 1.011 \mathrm{pu}$, and $0.977 \mathrm{pu}$, respectively, when the SMES is turned on. The overshoot and undershoot of the system frequency are minimized with the presence of the SMES system; moreover, the frequency fluctuations are reduced. The overshoot is minimized from 
$50.038 \mathrm{~Hz}$ (without SMES) to $50.005 \mathrm{~Hz}$ (with SMES). The undershoot is minimized from $49.965 \mathrm{~Hz}$ (without SMES) to $50.00 \mathrm{~Hz}$ (with SMES). This improvement of the frequency is a result of the SMES active power control, where the SMES injects / absorbs active power to/from the grid based on the value of the wind speed compared to the nominal wind speed. Moreover, power leveling is achieved based on the FLC-SMES, where the difference between the maximum and minimum value of active power at bus 18 and 33 and at the grid is reduced.

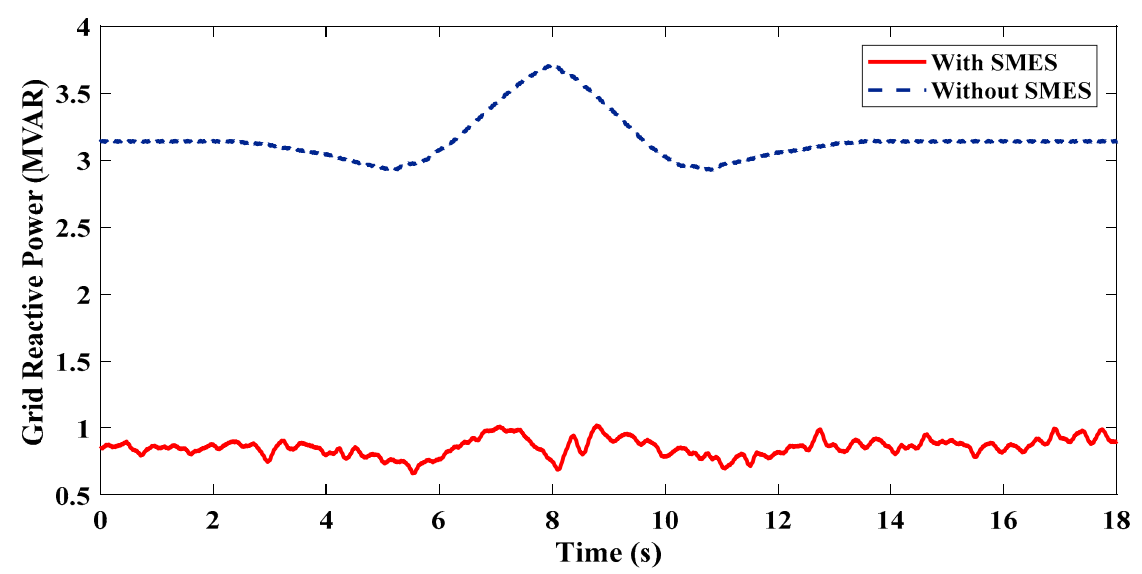

Figure 21. The grid reactive power.

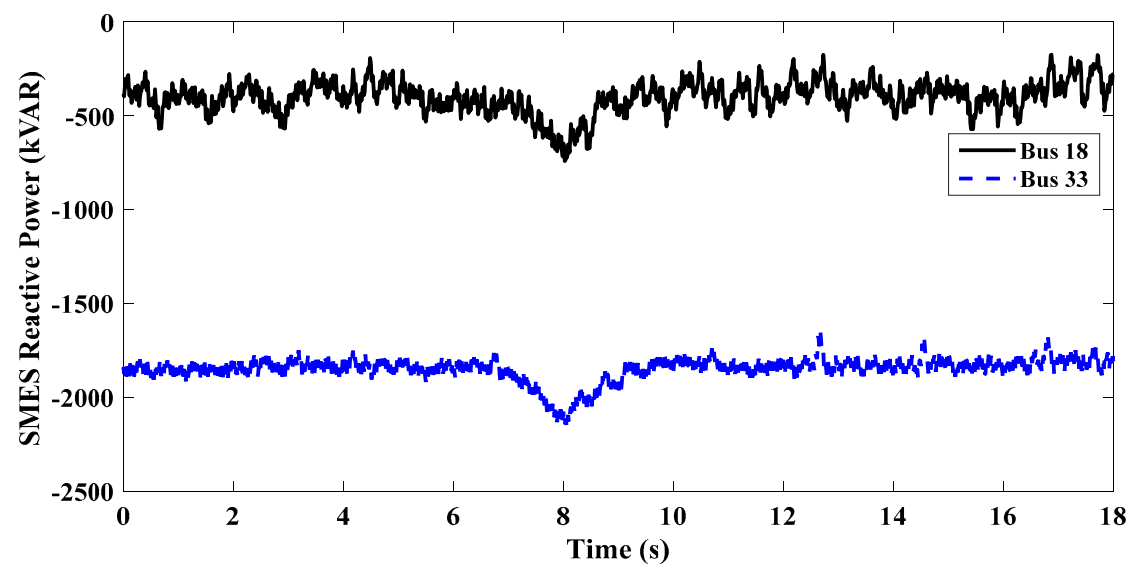

Figure 22. The SMES reactive power.

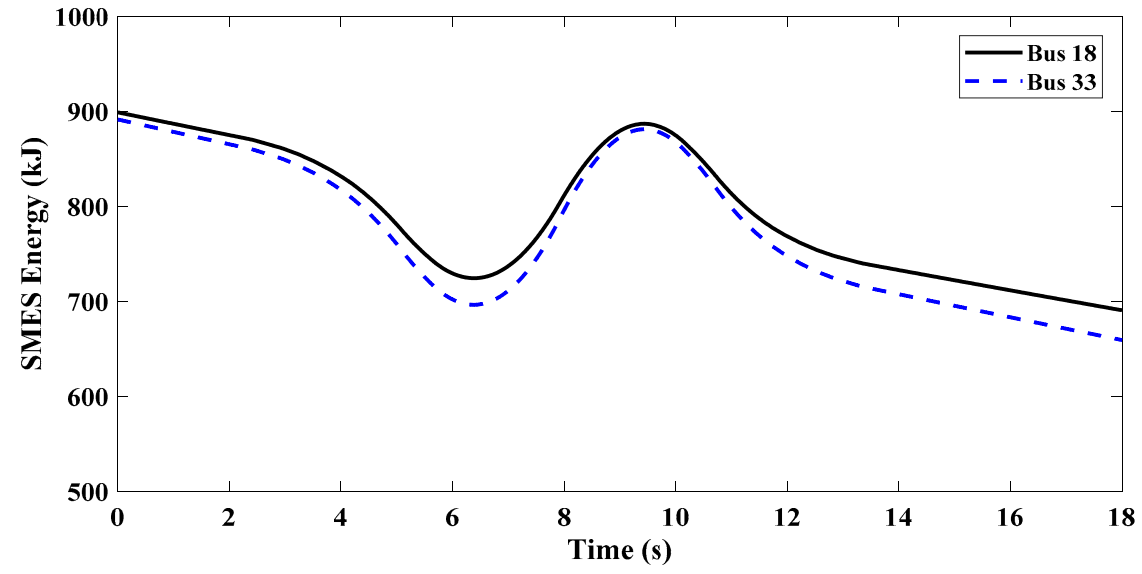

Figure 23. The SMES energy. 


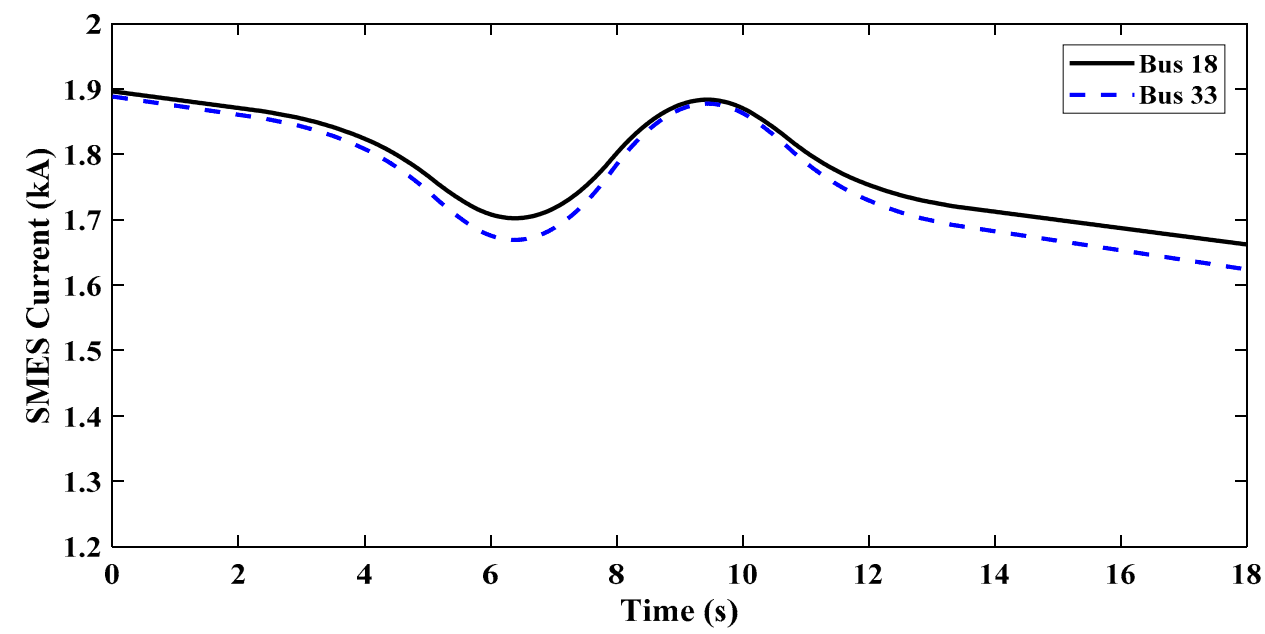

Figure 24. The SMES current.

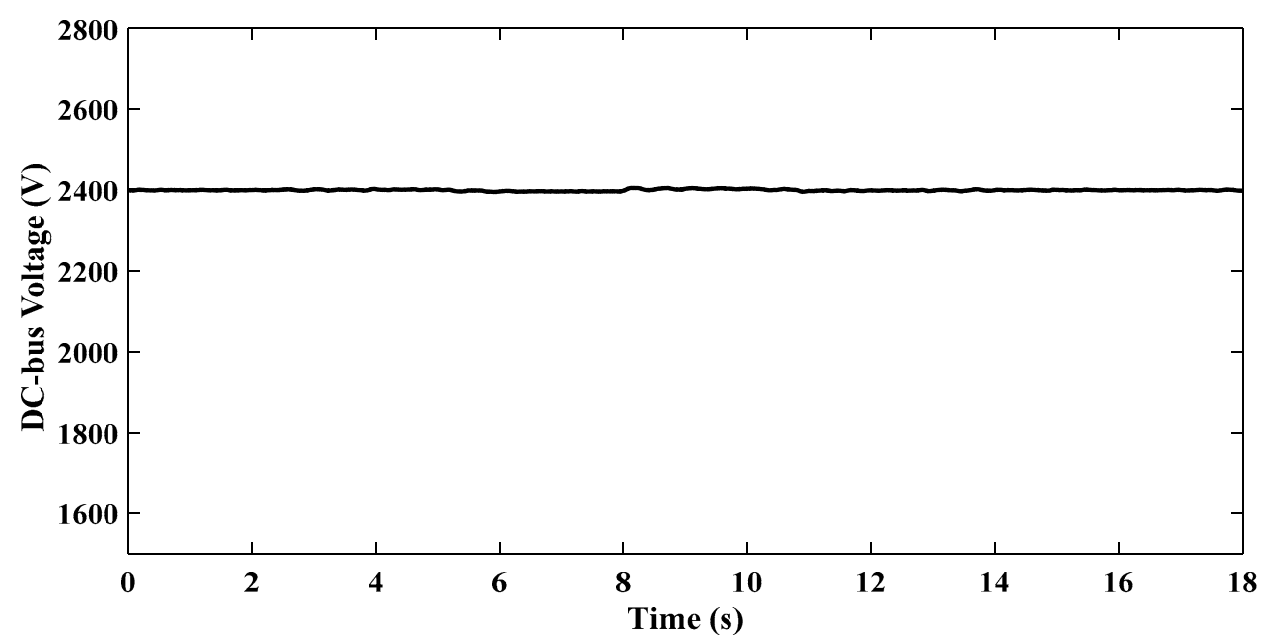

Figure 25. The DC-bus voltage.

Table 3. The numerical results of the unbalanced case.

\begin{tabular}{ccccc}
\hline & \multicolumn{2}{c}{ Without SMES } & \multicolumn{2}{c}{ With SMES } \\
\cline { 2 - 5 } & Maximum & Minimum & Maximum & Minimum \\
\hline Voltage at bus 18 $(\mathrm{pu})$, phase a & 0.990 & 0.950 & 1.036 & 1.019 \\
\hline Voltage at bus 18 $(\mathrm{pu})$, phase b & 0.960 & 0.920 & 1.035 & 1.012 \\
\hline Voltage at bus 18 $(\mathrm{pu})$, phase c & 0.920 & 0.890 & 1.007 & 0.993 \\
\hline Voltage at bus 33 (pu), phase a & 0.980 & 0.950 & 1.015 & 1.017 \\
\hline Voltage at bus 33 $(\mathrm{pu})$, phase b & 0.953 & 0.927 & 1.014 & 1.011 \\
\hline Voltage at bus 33 (pu), phase c & 0.916 & 0.890 & 0.980 & 0.977 \\
\hline Frequency (Hz) & 50.038 & 49.965 & 50.005 & 50.000 \\
\hline Active power at 18 (MW) & 0.650 & 0.250 & 0.420 & 0.390 \\
\hline Active power at 33 (MW) & 0.650 & 0.250 & 0.420 & 0.390 \\
\hline Grid active power (MW) & 3.270 & 1.880 & 2.890 & 2.660 \\
\hline Grid reactive power (MVAR) & 3.750 & 2.950 & 1.020 & 0.670 \\
\hline
\end{tabular}




\section{Conclusions}

This paper discusses an FLC-SMES technique to improve the balanced and unbalanced distribution system's performance connected to a wind-based SCIG. The proposed method successfully mitigated the voltage and frequency fluctuations during a wind gust. Moreover, the proposed method achieved power leveling for the grid and common buses (18 and 33). Furthermore, the active and reactive powers of the grid were reduced to maintain the grid's stability. The SMES system has three modes of operation, where the proposed control can operate the SMES in charging mode, discharging mode, and standby mode according to the actual wind speed and the SMES current. A possible further extension of this model is to examine hybrid energy storage systems with RESs, and the inclusion of electric vehicles to achieve energy management of electrical power systems. The main limitations of the proposed work are the high capital cost of the SMES system and preservation of the superconducting state of the SMES coil.

Author Contributions: Conceptualization, H.S.S.; methodology, I.V.; software, H.S.S.; validation, H.S.S. and I.V.; formal analysis, H.S.S.; investigation, I.V.; resources, H.S.S.; data curation, H.S.S.; writing-original draft preparation, H.S.S.; writing-review and editing, I.V.; visualization, I.V.; supervision, I.V.; project administration, I.V.; funding acquisition, I.V. All authors have read and agreed to the published version of the manuscript.

Funding: This research received no external funding.

Institutional Review Board Statement: Not applicable.

Informed Consent Statement: Not applicable.

Data Availability Statement: Not applicable.

Conflicts of Interest: The authors declare no conflict of interest.

\section{References}

1. Renewables Global Status Report-REN21. 2020. Available online: https://www.ren21.net/reports/global-status-report/?gclid= Cj0KCQjwwuD7BRDBARIsAK_5YhUmsAuLdVfGwLa7hW6bd3_1oaBBaUdcPE9s9tQm6SAY0CWkk-nB1ZAaAlHREALw_ wcB (accessed on 3 October 2020).

2. Eminoglu, U. A New Model for Wind Turbine Systems. Electr. Power Components Syst. 2009, 37, 1180-1193. [CrossRef]

3. Li, C.; University of Birmingham; Deng, J.; Zhang, X.-P. Coordinated design and application of robust damping controllers for shunt FACTS devices to enhance small-signal stability of large-scale power systems. CSEE J. Power Energy Syst. $2017,3,399-407$. [CrossRef]

4. Wan, Y.; Murad, M.A.A.; Liu, M.; Milano, F. Voltage Frequency Control Using SVC Devices Coupled with Voltage Dependent Loads. IEEE Trans. Power Syst. 2018, 34, 1589-1597. [CrossRef]

5. Pereira, R.; Ferreira, C.M.M.; Barbosa, F.M. Comparative study of STATCOM and SVC performance on Dynamic Voltage Collapse of an Electric Power System with Wind Generation. IEEE Lat. Am. Trans. 2014, 12, 138-145. [CrossRef]

6. Kumar, H.; Dahiya, R. FACTS Device Control Strategy Using Optimal Number of PMU. In Proceedings of the International Conference on Advances in Electronics, Electrical \& Computational Intelligence (ICAEEC), Prayagraj, India, 31 May-1 June 2019.

7. Li, C.; Disfani, V.R.; Pecenak, Z.K.; Mohajeryami, S.; Kleissl, J. Optimal OLTC voltage control scheme to enable high solar penetrations. Electr. Power Syst. Res. 2018, 160, 318-326. [CrossRef]

8. Gu, M.; Meegahapola, L.G.; Wong, A.K.L. Coordinated Voltage and Frequency Control in Hybrid AC/MT-HVDC Power Grids for Stability Improvement. IEEE Trans. Power Syst. 2021, 36, 635-647. [CrossRef]

9. Sanampudi, N.; Kanakasabapathy, P. Integrated voltage control and frequency regulation for stand-alone micro-hydro power plant. Mater. Today Proc. 2021. [CrossRef]

10. Babaei, M.; Muyeen, S.; Islam, S. Transiently stable intentional controlled islanding considering post-islanding voltage and frequency stability constraints. Int. J. Electr. Power Energy Syst. 2021, 127, 106650. [CrossRef]

11. Haider, W.; Hassan, S.J.U.; Mehdi, A.; Hussain, A.; Adjayeng, G.O.M.; Kim, C.-H. Voltage Profile Enhancement and Loss Minimization Using Optimal Placement and Sizing of Distributed Generation in Reconfigured Network. Machines 2021, 9, 20. [CrossRef]

12. Shigenobu, R.; Nakadomari, A.; Hong, Y.-Y.; Mandal, P.; Takahashi, H.; Senjyu, T. Optimization of Voltage Unbalance Compensation by Smart Inverter. Energies 2020, 13, 4623. [CrossRef]

13. Xu, H.; Wang, C.; Lu, C.; Lu, Z. An adaptive wind power smoothing method with energy storage system. IEEE Power Energy Soc. Gen. Meet. 2014, 1-5. [CrossRef] 
14. Shin, S.-S.; Oh, J.-S.; Jang, S.-H.; Cha, J.-H.; Kim, J.-E. Active and Reactive Power Control of ESS in Distribution System for Improvement of Power Smoothing Control. J. Electr. Eng. Technol. 2017, 12, 1007-1015. [CrossRef]

15. Zhang, Y.; Srivastava, A. Voltage Control Strategy for Energy Storage System in Sustainable Distribution System Operation. Energies 2021, 14, 832. [CrossRef]

16. Gong, K.; Shi, J.; Liu, Y.; Wang, Z.; Ren, L.; Zhang, Y. Application of SMES in the Microgrid Based on Fuzzy Control. IEEE Trans. Appl. Supercond. 2016, 26, 1-5. [CrossRef]

17. Wang, Z.; Zou, Z.; Zheng, Y. Design and Control of a Photovoltaic Energy and SMES Hybrid System with Current-Source Grid Inverter. IEEE Trans. Appl. Supercond. 2013, 23, 5701505. [CrossRef]

18. Hutchinson, A.; Gladwin, D.T. Optimisation of a wind power site through utilisation of flywheel energy storage technology. Energy Rep. 2020, 6, 259-265. [CrossRef]

19. Ruddell, A. Flywheel energy storage technologies for wind energy systems. In Stand-Alone and Hybrid Wind Energy Systems; Elsevier: Amsterdam, The Netherlands, 2010; pp. 366-392.

20. He, G.; Chen, Q.; Kang, C.; Xia, Q.; Poolla, K. Cooperation of Wind Power and Battery Storage to Provide Frequency Regulation in Power Markets. IEEE Trans. Power Syst. 2017, 32, 3559-3568. [CrossRef]

21. Kang, B.-K.; Kim, S.-T.; Bae, S.-H.; Park, J.-W. Effect of a SMES in Power Distribution Network With PV System and PBEVs. IEEE Trans. Appl. Supercond. 2013, 23, 5700104. [CrossRef]

22. Salama, H.; Vokony, I. Comparison of different electric vehicle integration approaches in presence of photovoltaic and superconducting magnetic energy storage systems. J. Clean. Prod. 2020, 260, 121099. [CrossRef]

23. Aly, M.M.; Salama, H.; Abdel-Akher, M. Power control of fluctuating wind/PV generations in an isolated Microgrid based on superconducting magnetic energy storage. In Proceedings of the 2016 Eighteenth International Middle East Power Systems Conference (MEPCON), Cairo, Egypt, 27-29 December 2016; pp. 419-424.

24. Salama, H.S.; Said, S.M.; Vokony, I.; Hartmann, B. Adaptive Coordination Strategy Based on Fuzzy Control for Electric Vehicles and Superconducting Magnetic Energy Storage-Towards Reliably Operating Utility Grids. IEEE Access 2021, 9, 61662-61670. [CrossRef]

25. Yang, B.; Wang, J.; Zhang, X.; Yu, L.; Shu, H.; Yu, T.; Sun, L. Control of SMES systems in distribution networks with renewable energy integration: A perturbation estimation approach. Energy 2020, 202, 117753. [CrossRef]

26. Kumar, G.S.; Selvi, V.A.I.; Pandiyan, K. Design and analysis of ML-VSC based SMES with improved power quality features. Mater. Today Proc. 2021. [CrossRef]

27. Salama, H.; Vokony, I.; Zobair, M.; Aly, M.M. Amelioration the Stability of Power System Coupled with SCIG and PMSG Using Controlled-SMES. In Proceedings of the 2020 International Conference on Innovative Trends in Communication and Computer Engineering (ITCE), Aswan, Egypt, 8-9 February 2020; pp. 346-351.

28. Salama, H.S.; Vokony, I. Power Stability Enhancement of SCIG and DFIG Based Wind Turbine Using Controlled-SMES. Int. J. Renew. Energy Res. 2019, 9, 147-156.

29. Mateev, V.; Ivanov, G.; Marinova, I. Comparison of Electromagnetic Formulations for Multilayer HTS Power Cable Modeling. In Proceedings of the 2020 21st International Symposium on Electrical Apparatus \& Technologies (SIELA), Bourgas, Bulgaria, 3-6 June 2020; pp. 1-4.

30. Mir, A.S.; Senroy, N. Adaptive Model Predictive Control Scheme for Application of SMES for Load Frequency Control. IEEE Trans. Power Syst. 2017, 1. [CrossRef]

31. Xian, W.; Yuan, W.; Yan, Y.; Coombs, T.A. Minimize frequency fluctuations of isolated power system with wind farm by using superconducting magnetic energy storage. In Proceedings of the 2009 International Conference on Power Electronics and Drive Systems (PEDS), Taipei, Taiwan, 2-5 November 2009; pp. 1329-1332.

32. Krishnamurthy, V.; Kumar, C.R. Constant Power Control Of 15 DFIG Wind Turbines with Superconducting Magnetic Energy Storage System. Int. J. Eng. Trends Technol. 2013, 4, 4193-4200.

33. Ali, M.H.; Park, M.; Yu, I.-K.; Murata, T.; Tamura, J. Improvement of Wind-Generator Stability by Fuzzy-Logic-Controlled SMES. IEEE Trans. Ind. Appl. 2009, 45, 1045-1051. [CrossRef]

34. Ali, M.H.; Park, M.; Yu, I.-K.; Murata, T.; Tamura, J.; Wu, B. Enhancement of transient stability by fuzzy logic-controlled SMES considering communication delay. Int. J. Electr. Power Energy Syst. 2009, 31, 402-408. [CrossRef]

35. Ozmetin, A.E.; Rathnayaka, K.D.D.; Naugle, D.G.; Lyuksyutov, I.F. Strong increase in critical field and current in magnetsuperconductor hybrids. J. Appl. Phys. 2009, 105, 07E324. [CrossRef]

36. Tsuchiya, K.; Kikuchi, A.; Terashima, A.; Norimoto, K.; Uchida, M.; Tawada, M.; Masuzawa, M.; Ohuchi, N.; Wang, X.; Takao, T.; et al. Critical current measurement of commercial REBCO conductors at $4.2 \mathrm{~K}$. Cryogenics 2017, 85, 1-7. [CrossRef]

37. Amaro, N.; Pina, J.M.; Martins, J.; Ceballos, J.M. A Study on Superconducting Coils for Superconducting Magnetic Energy Storage (SMES) Applications; Springer: Berlin/Heidelberg, Germany, 2013; pp. 449-456.

38. Glatz, A.; Sadovskyy, I.A.; Welp, U.; Kwok, W.-K.; Crabtree, G.W. The Quest for High Critical Current in Applied HighTemperature Superconductors. J. Supercond. Nov. Magn. 2019, 33, 127-141. [CrossRef]

39. Skiba, B.; Tomkow, L.; Kulikov, E.; Drobin, V.; Malecha, Z. Experimental and numerical analysis of faulty operation of a superconducting solenoid made of tape with high temperature superconductor. AIP Conf. Proc. 2019, $2163,20004$.

40. Rupa, J.; Ganesh, S. Power Flow Analysis for Radial Distribution System Using Backward/Forward Sweep Method. Int. J. Electr. Comput. Electron. Commun. Eng. 2014, 8, 1540-1544. 
41. Venkatesh, B.; Chandramohan, S.; Kayalvizhi, N.; Devi, R.K. Optimal reconfiguration of radial distribuion system using artificial intelligence methods. In Proceedings of the 2009 IEEE Toronto International Conference Science and Technology for Humanity (TIC-STH), Toronto, ON, Canada, 26-27 September 2009; pp. 660-665.

42. Firouzi, M.; Gharehpetian, G.B.; Mozafari, S.B. Application of UIPC to improve power system stability and LVRT capability of SCIG-based wind farms. IET Gener. Transm. Distrib. 2017, 11, 2314-2322. [CrossRef]

43. Salama, H.S.; Said, S.M.; Aly, M.; Vokony, I.; Hartmann, B. Studying Impacts of Electric Vehicle Functionalities in Wind Energy-Powered Utility Grids With Energy Storage Device. IEEE Access 2021, 9, 45754-45769. [CrossRef]

44. Heier, S. Grid Integration of Wind Energy; Wiley: Hoboken, NJ, USA, 2014.

45. Tan, S.; Geng, H.; Yang, G.; Wang, H.; Blaabjerg, F. Modeling framework of voltage-source converters based on equivalence with synchronous generator. J. Mod. Power Syst. Clean Energy 2018, 6, 1291-1305. [CrossRef]

46. Segundo, J.; Peña-Gallardo, R.; Medina, A.; Núñez-Gutiérrez, C.; Visairo-Cruz, N. A Comprehensive Modeling of a Three-Phase Voltage Source PWM Converter. Math. Probl. Eng. 2015, 2015, 1-11. [CrossRef] 